Prepared for the U.S. Department of Energy under Contract DE-AC05-76RL01830

\title{
Effective Permeability Change in Wellbore Cement with Carbon Dioxide Reaction
}

W Um

HB Jung

PF Martin

BP McGrail

November 2011

Pacific Northwest

NATIONAL LABORATORY

Proudly Operated by Battelle Since 1965 


\title{
DISCLAIMER
}

This report was prepared as an account of work sponsored by an agency of the Lnited States Government. Neitler the United States Government nor any agency thereof, nor Battelle Memorial Institute, nor any of their emplos ces. makes any warranty, express or implied, or assumes any legal liability or responsibility for the accuracy, completeness, or usefulness of any information, apparatus, product, or process disclosed, or represents that its use would not infringe privately owned rights. Reference herein to any specific commercial product. process. or sen ice by trade name, trademark. manufacturer. or othenvise does not necessarily constitute or imply its endorsement, recommendation or favoring by the United States Government or any agency thereof, or Batlelle Menorial Instifute. The views and opinions of anthors expressed herein do not necessarily state or reflect those of the United States Govermment or any agency thereof.

\author{
PACIFIC NORTHWEST NATIONAL, I.ABORATORY \\ operated bv \\ BATTITIE \\ for the \\ LNITED STATES DEPARTMENT OF ENERGY \\ under (ontract DF:-1C05-76RLO1830
}

Printed in the l nited States of Anerica
Available to DOF. and DOF contractors from the Office of Scientific and T'rchnical lnformation,
P.O. Box 62, Oak Ridge, TY 37831-0062; ph: (865) 5768401 fax: $(865) 5765728$
entail: reportsinatonis.osti.gor

Available to the public from the National Techuical Information Service 5301 Shawnee Rd., Alexandria, VA 22312

ph: (800) 553-NTIS (6847)

email: onders àntis.gov <http:/www.ntis.gov/about/form.aspx>

Online ordering: http://www.ntis.gov 


\title{
Effective Permeability Change in Wellbore Cement with Carbon Dioxide Reaction
}

\author{
W Um \\ HB Jung \\ PF Martin \\ BP McGrail
}

November 2011

Prepared for

the U.S. Department of Energy

under Contract DE-AC05-76RL01830

Pacific Northwest National Laboratory

Richland, Washington 99352 



\section{Summary}

Portland cement, a common sealing material used in wellbores for geological carbon sequestration, was reacted with carbon dioxide $\left(\mathrm{CO}_{2}\right)$ in supercritical, gaseous, and aqueous phases at various pressure and temperature conditions to simulate cement $-\mathrm{CO}_{2}$ reaction along the wellbore from carbon injection depth to the near surface. Hydrated Portland cement columns (14 mm diameter $\times 90 \mathrm{~mm}$ long; water-tocement ratio $=0.33$ ), including additives such as steel coupons and Wallula basalt fragments, were reacted with $\mathrm{CO}_{2}$ in the wet supercritical (the top half) and dissolved (the bottom half) phases under carbon sequestration conditions with high pressure $(10 \mathrm{MPa})$ and temperature $\left(50^{\circ} \mathrm{C}\right)$ for 5 months. In parallel, small-sized hydrated Portland cement columns $(7 \mathrm{~mm}$ diameter $\times 20 \mathrm{~mm}$ long; water-to-cement ratio $=0.38)$ were reacted with $\mathrm{CO}_{2}$ in a dissolved phase at high pressure $(10 \mathrm{MPa})$ and temperature $\left(50^{\circ} \mathrm{C}\right)$ for 1 month or with wet $\mathrm{CO}_{2}$ in gaseous phase at low pressure $(0.1 \mathrm{MPa})$ and temperature $\left(20^{\circ} \mathrm{C}\right)$ for 3 months. X-ray microtomography images reveal the cement that reacted with $\mathrm{CO}_{2}$ saturated groundwater had degradation depth of $\sim 1 \mathrm{~mm}$ for 1 month and $\sim 3.5 \mathrm{~mm}$ for 5 months, whereas the degradation was minor with cement exposure to supercritical $\mathrm{CO}_{2}$. Scanning electron microscopy-energy dispersive spectroscopy analysis showed the carbonated cement was comprised of three distinct zones: the innermost less degraded zone with $\mathrm{Ca}$ atom $\%>\mathrm{C}$ atom $\%$, the inner degraded zone with $\mathrm{Ca}$ atom $\%$ $\approx \mathrm{C}$ atom $\%$ due to precipitation of calcite, the outer degraded zone with $\mathrm{C}$ atom $\%>\mathrm{Ca}$ atom $\%$ due to dissolution of calcite and C-S-H, as well as adsorption of carbon to cement matrix. The outer degraded zone of carbonated cement was porous and fractured because of dissolution-dominated reaction by carbonic acid exposure, which resulted in the increase in BJH (Barrett-Joyner-Halenda) pore volume and BET (Brunauer-Emmett-Teller) surface area. In contrast, cement-wet $\mathrm{CO}_{2}(\mathrm{~g})$ reaction at low $\mathrm{P}(0.1$ $\mathrm{MPa})-\mathrm{T}\left(20^{\circ} \mathrm{C}\right)$ conditions for 1 to 3 months was dominated by precipitation of micron-sized calcite on the outside surface of cement, which resulted in the decrease in BJH pore volume and BET surface area. Cement carbonation and pore structure change are significantly dependent on pressure and temperature conditions, as well as the phase of $\mathrm{CO}_{2}$, which controls the balance between precipitation and dissolution in cement matrix. Geochemical modeling result suggests that ratio of solid (cement)-to-solution (carbonated water) has a significant effect on cement carbonation; thus, the cement- $\mathrm{CO}_{2}$ reaction experiment needs to be conducted under realistic conditions representing the in-situ wellbore environment of a carbon sequestration field site.

Total porosity and air permeability for a duplicate cement column with water-to-cement ratio of 0.38 measured after oven drying by Core Laboratories using Boyle's Law technique and steady-state method were $31 \%$ and $0.576 \mathrm{mD}$. A novel method to measure the effective liquid permeability of a cement column using X-ray microtomography images after injection of pressurized potassium iodide (KI) is under development by Pacific Northwest National Laboratory. Preliminary results indicate the permeability of an unreacted cement column with water-to-cement ratio of 0.38 is $4 \sim 8 \mu \mathrm{D}$. Pacific Northwest National Laboratory will apply the method to understand the effective permeability change of Portland cement by $\mathrm{CO}_{2}(\mathrm{~g})$ reaction under a variety of pressure and temperature conditions to develop a more reliable well-bore leakage risk model. 



\section{Acknowledgments}

The authors are grateful to Toni Owen and Danielle Jansik for XMT analyses, Mark Bowden for micro XRD analysis, and Kent Parker for BJH and BET analyses. The authors also would like to acknowledge Laxmikant Saraf for sample analyses by SEM-EDS. 



\section{Acronyms and Abbreviations}

$\begin{array}{ll}\text { BET } & \text { Brunauer-Emmett-Teller } \\ \text { BJH } & \text { Barrett-Joyner-Halenda } \\ \text { EDS } & \text { energy dispersive spectroscopy } \\ \text { ICP-AES } & \text { inductively coupled plasma atomic emission spectroscopy } \\ \text { NCS } & \text { net confining stresses } \\ \text { PNNL } & \text { Pacific Northwest National Laboratory } \\ \text { SEM-EDS } & \text { scanning electron microscopy-energy dispersive spectroscopy } \\ \text { XMT } & \text { X-ray microtomography } \\ \text { XRD } & \text { X-ray diffraction }\end{array}$





\section{Contents}

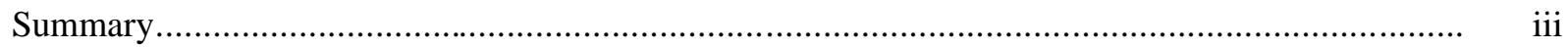

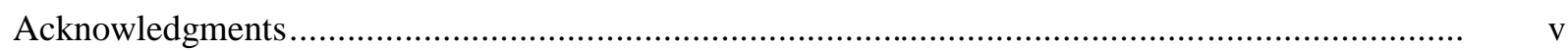

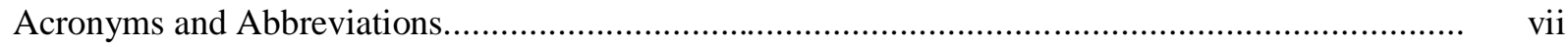

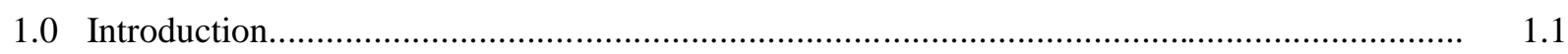

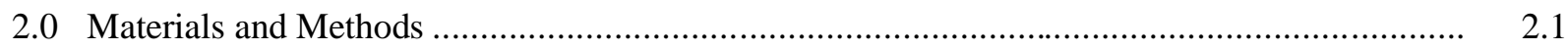

2.1 High Pressure and Temperature Experiment ……................................................... 2.1

2.2 Low Pressure and Temperature Experiment …….................................................... 2.2

2.3 Effective Liquid Permeability Measurement by Pressurized Potassium Iodide Injection... $\quad 2.2$

2.4 Porosity and Air Permeability Measurement ……........................................................ 2.2

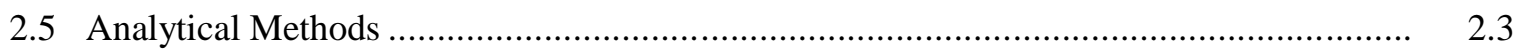

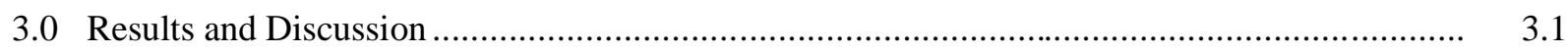

3.1 High Pressure and Temperature Experiment …......................................................... 3.1

3.1.1 Aqueous Chemical Composition Change............................................................... 3.1

3.1.2 Solid Chemical Composition and Pore Structure Change...................................... 3.3

3.2 Low Pressure and Temperature Experiment ......................................................... 3.17

3.3 Effective Liquid Permeability Measurement by X-Ray Microtomography Image of Potassium Iodide (KI) Injection ................................................................................. 3.19

3.4 Geochemical Modeling of Cement Degradation ........................................................ 3.21

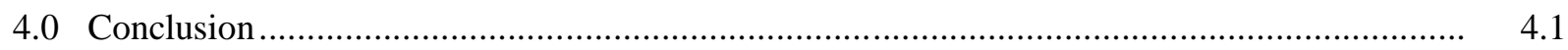

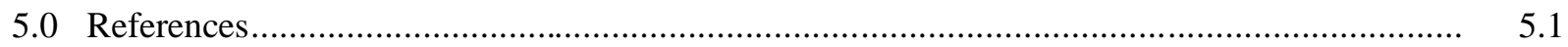




\section{Figures}

3.1. Change of Chemical Composition of Artificial Groundwater by $\mathrm{CO} 2$ Reaction with Cement in Combination with Steel Coupon and Basalt Under High P-T Condition $\left(10 \mathrm{MPa}+50^{\circ} \mathrm{C}\right)$ for 5 Months (vessel 1-4) and 1 Month (vessel 5). Vessel 1 and 2: artificial groundwater $(130 \mathrm{~mL})+2$ cement columns including corroded or uncorroded steel coupons; vessel 3 and 4: artificial groundwater $(130 \mathrm{~mL})+3$ cement column with layered cracks or basalts or without additive; vessel 5: artificial groundwater $(130 \mathrm{~mL})+1$ cement column without additive

3.2. XRD Pattern for Precipitates in Aqueous Samples Collected from Four High P-T Vessels by Filtration through a $0.45-\mu \mathrm{m}$ Membrane Filter after $\mathrm{CO}_{2}$ Reaction for 3 and 20 Days. The precipitates are identified as $100 \%$ calcite.

3.3. (A) The Cross-Section of a Cement Column (NRAP cement-2; $7 \mathrm{~mm} \mathrm{D} \times 20 \mathrm{~mm} \mathrm{~L}$ ) Reacted with $\mathrm{CO}_{2}$-Saturated Synthetic Groundwater; (B) SEM Image of the Cross-Section of the Cement Column with the Position of EDS Analysis with a Dashed Line Indicating Approximate Degradation Zone; (C) Table of SEM-EDS Analyses (atom \%) for Four Positions Indicated in the SEM Image

3.4. SEM-EDS Image of the Outside Surface of NRAP Cement-2 Showing Cracks and Pores After Reaction with $\mathrm{CO}_{2}$-Saturated Synthetic Groundwater Under High P-T For 1 Month (left) and Cumulative BJH Pore Volume and BJH Surface Area for NRAP Cement-2 Before and After the Reaction (right)

3.5. XMT Images of a Small-sized Cement Column in Vessel 5 before A) Vertical Crosssection; B) Horizontal Cross-section; and after C) Vertical cross-section; D) Horizontal cross-section Reaction with $\mathrm{CO}_{2}$ Saturated Synthetic Groundwater for 1 Month

3.6. Photos of Cement Columns Before (top) and After (bottom) $\mathrm{CO}_{2}$ Reaction Under High P-T in Vessels 1 (cement column \#3 and 6) and 2 (cement column \#4 and 8).

3.7. Photos of Cement Columns Before (top) and After (bottom) $\mathrm{CO}_{2}$ Reaction Under High P-T in Vessels 3 (cement column \#11, 15, and 23) and 4 (cement column \#10, 16, and 24)....

3.8. The Cross-Section of Cement Columns Reacted with Supercritical $\mathrm{CO}_{2}(\mathrm{~A})$ and $\mathrm{CO}_{2}$-Saturated Synthetic Groundwater (B)

3.9. SEM Images of the Cross-Section of Cement Columns (NRAP-3, 6, and 15) and EDS Analyses Showing Spatial Change of Cement Chemical Composition

3.10. SEM Images and EDS Mapping for the NRAP-15 Cement Column Reacted with $\mathrm{CO}_{2}$-Saturated Synthetic Groundwater (top and middle) and with Supercritical $\mathrm{CO}_{2}$ (bottom).

3.11. SEM Images and EDS Mapping for NRAP-3 (A) and NRAP-6 Cement Columns (B), and Atom \% of $\mathrm{Ca}$ and $\mathrm{C}$ as well as $\mathrm{Ca} / \mathrm{C}$ atom \% Ratio by Line Scan for NRAP-6 (C)

3.12. XMT Images of Cement Column (NRAP-16) after Reaction with Supercritical $\mathrm{CO}_{2}$ (left) and $\mathrm{CO}_{2}$ (right) Saturated Water for 5 Months.

3.13. Cumulative BJH Pore Volume and Surface Area as a Function of Pore Diameter after Cement Reaction with Supercritical $\mathrm{CO}_{2}$ (left) and $\mathrm{CO}_{2}$ Saturated Water (right); Cumulative BJH Pore Volume and Surface Area Prior to the Reaction is Also Indicated in Orange Symbols.

3.14. SEM Image Showing the Micron-Sized Calcite Precipitation on the Cement Surface After $\mathrm{CO}_{2}(\mathrm{~g})$ Reaction for 1 Month (top left) and 3 Months (top right), as well as XRD Pattern Showing Calcite as a Major Precipitate, as well as Vaterite as a Minor Precipitate (bottom).... 
3.15. Change of Cumulative BJH Pore Volume and Surface Area as a Function of Pore Width as the Result of Moisturized $\mathrm{CO}_{2}(\mathrm{~g})$ Reaction for 1 to 3 Months

3.16. SEM Images and EDS Data for Horizontal Cross-Section of a Cement Column After $\mathrm{CO}_{2}(\mathrm{~g})$ Reaction for 3 Months; Spectrum 1 is from the Center of the Cross-Section

3.17. XMT Images Showing the Effect of KI Solution on the Contrast Between Liquid-Filled Pores and Solid Phase in Cement Samples.

3.18. XMT Image Showing the Advection of KI Solution (30 wt.\%; bright color) Through Pores of a Cement Column (water-to-cement ratio $=0.38$ ) at 9 psi for 114 Hours

3.19. Bulk Geochemical Reaction Modeling of Cement Columns in (A) Vessel 1-4 and (B) Vessel 5 by $\mathrm{CO}_{2}$ Saturated Water at $50^{\circ} \mathrm{C}$ and $10 \mathrm{MPa}$, As Well As (C) the Saturation Index with Respect to Calcite as a Function of Solid-to-Solution Ratio.

3.20. One-Dimensional Transport Geochemical Modeling of Cement Degradation by $\mathrm{CO}_{2}$ Saturated Water at $50^{\circ} \mathrm{C}$ and $10 \mathrm{MPa}$ as a Function of Penetration Depth in Vessel 3 or 4

3.21. One-Dimensional Transport Geochemical Modeling of Cement Degradation by $\mathrm{CO}_{2}$ Saturated Water at $50^{\circ} \mathrm{C}$ and $10 \mathrm{MPa}$ as a Function of Penetration Depth in Vessel 5

\section{Tables}

2.1. Chemical Composition of Artificial Groundwater

2.2. Description of Cement Columns for High P-T Experiment

3.1. BJH Pore Volume and BET Surface Area Change by $\mathrm{CO}_{2}$ for 1 Month and 3 Months at Low and High P-T Conditions.

3.2. BJH Pore Volume and BET Surface Area Before and After Cement- $\mathrm{CO}_{2}$ Reaction for 5 Months at High P-T Condition

3.3. SEM-EDS for a Cement Column for Low P-T Experiment Before and After $\mathrm{CO}_{2}$ Reaction 



\subsection{Introduction}

Industrialization since the $18^{\text {th }}$ century has increased the atmospheric carbon dioxide $\left(\mathrm{CO}_{2}\right)$ concentration from 280 parts per million ( $\mathrm{ppm}$ ) to $380 \mathrm{ppm}$ by combustion of fossil fuels, which is theorized to contribute to global warming (Bruant et al. 2002; Solomon et al. 2007). $\mathrm{CO}_{2}$ capture and storage in geologic formations, including oil and gas reservoirs, deep saline aquifers, coal seams, and salt caverns (Gasda et al. 2004) have been proposed to decrease atmospheric $\mathrm{CO}_{2}$ concentrations. The injection of $\mathrm{CO}_{2}$ into deep saline aquifers offers advantages because deep saline formations are widely distributed, and provide great global storage capacity-approximately between 10,000 and 200,000 gigatonne (Gt) $\mathrm{CO}_{2}$, which accounts for hundreds to thousands of years of $\mathrm{CO}_{2}$ emissions (Bruant et al. 2002). In addition, the technology for $\mathrm{CO}_{2}$ injection into geologic formations has been practiced for enhanced oil and gas recovery operations for decades (Bachu and Watson 2009).

$\mathrm{CO}_{2}$ in deep subsurface formations will exist as a dense fluid, whether in liquid or supercritical phases, and the density of $\mathrm{CO}_{2}$ will be $200 \sim 750 \mathrm{~kg} / \mathrm{m}^{3}$, depending on pressure and temperature conditions, while viscosity will be 5 to 40 times less than the saline groundwater (Bachu 2003). Because of the buoyancy effect resulting from the difference in density between supercritical $\mathrm{CO}_{2}$ and saline groundwater, injected $\mathrm{CO}_{2}$ tends to escape upward into overlying formations and potentially to the land surface through the zone of higher permeability (Gasda et al. 2004). Therefore, long-term sustainability of $\mathrm{CO}_{2}$ storage in deep saline aquifers must be demonstrated to protect the environment and human health. For permanent or long-term storage of $\mathrm{CO}_{2}$ in geologic formations, the risk for leakage of $\mathrm{CO}_{2}$ through wellbores needs to be evaluated because leakage rates of less than $1 \%$ of stored $\mathrm{CO}_{2}$ per 100 years are required for geologic sequestration to be viable (DOE 2007). $\mathrm{CO}_{2}$ leakage through wellbores can adversely affect underground sources of drinking water and consequently human health, as well as the ecosystem (Bruant et al. 2002; Wilkin and Digiulio 2010; Little and Jackson 2010), particularly in a region with a high density of wells (e.g., $>10 \mathrm{wells} / \mathrm{km}^{2}$ ) that extends from Texas north to Alberta, Canada (Gasda et al. 2004).

Portland cement is usually used as a sealing material for wellbores for geological carbon sequestration. Wells are typically constructed with steel casing and Portland cement slurry is placed in the annulus between steel casing and formation rock to prevent vertical fluid migration and provide mechanical support (Kutchko et al. 2009). Abandoned wells are typically sealed with cement plugs inside the casing to block the vertical migration of fluids. Portland cement contains four major crystalline compounds: tricalcium silicate $\left(\mathrm{Ca}_{3} \mathrm{SiO}_{5}\right)$, dicalcium silicate $\left(\mathrm{Ca}_{2} \mathrm{SiO}_{4}\right)$, tricalcium aluminate $\left(\mathrm{Ca}_{3} \mathrm{Al}_{2} \mathrm{O}_{6}\right)$, and tetracalcium aluminoferrite $\left(\mathrm{Ca}_{4} \mathrm{Al}_{2} \mathrm{Fe}_{2} \mathrm{O}_{10}\right)$ (Kutchko et al. 2007). Hydrated products formed by mixing Portland cement with water are calcium-silicate-hydrate (C-S-H), a semi-amorphous gel-like material and calcium hydroxide $\left(\mathrm{Ca}(\mathrm{OH})_{2(\mathrm{~s})}\right)$, a crystalline phase (Nelson 1990; Neville 2004). Wellbore integrity could be negatively affected by poor completion or abandonment, formation damage around the wellbore, geomechanical effects, geochemical degradation of well cements, casing corrosion, and casing failure as a result of thermal or mechanical stresses (Bachu and Bennion 2009). Potential leakage pathways of $\mathrm{CO}_{2}$ may occur at the interface between casing and cement, cement plug and casing, and cement and host rock, or through the cement pore space and fracture (Gasda et al. 2004). Carbonation of cement that results from solvation of calcium ions from the solid phase by diffused carbon dioxide and precipitation of calcium carbonate can affect chemical and physical properties of cement (Fernandez Bertos et al. 2004). There has been disagreement regarding the degree of cement degradation as the result of reaction with $\mathrm{CO}_{2}$. Wellbore cement has been shown to be susceptible to $\mathrm{CO}_{2}$ attack, leading to rapid 
degradation (Scherer et al. 2005; Barlet-Gouédard et al. 2006). In contrast, other studies suggested that $\mathrm{CO}_{2}$ penetration and reaction with cement is limited (Kutchko et al. 2007, 2008), and the long-term performance of wellbore cement in a $\mathrm{CO}_{2}$-enhanced oil recovery field was good, providing an effective barrier to significant fluid flow for decades (Crow et al. 2010). The rate of cement degradation can be variable depending on the $\mathrm{pH}$ of $\mathrm{CO}_{2}$-saturated groundwater, which is affected by aquifer types (e.g., sandstone formation, limestone formation) (Duguid and Scherer 2010). Despite numerous previous studies reporting the geochemical and mineralogical alteration of well cement by $\mathrm{CO}_{2}$ under geologic sequestration conditions (Kutchko et al. 2007, 2008, 2009; Rimmele et al. 2008; Wigand et al. 2009), the pore structure and permeability change of cement as a result of cement- $\mathrm{CO}_{2}$ reaction under various pressure-temperature conditions is poorly understood. Bachu and Bennion (2009) reported the decrease in permeability from 0.1 to $0.01 \mu \mathrm{D}$ for Type G Portland cement exposed to through-flowing $\mathrm{CO}_{2}$ saturated water at a fluid pressure of $15 \mathrm{MPa}$, a confining pressure of $29 \mathrm{MPa}$, and a temperature of $65^{\circ} \mathrm{C}$ for 90 days. Liteanu and Spiers (2011) showed that permeability of intact Class A Portland cement cylinders reacted with supercritical $\mathrm{CO}_{2}$ for a total duration of 3 months under a constant confining pressure of $30 \mathrm{MPa}$, a temperature of $80^{\circ} \mathrm{C}$ and a $\mathrm{CO}_{2}$ pressure of $10 \mathrm{MPa}$, decreased with time from about 0.18 to $0.008 \mathrm{mD}$.

Laboratory data for pore structure changes of Portland cement as a result of chemical and mineralogical degradation by $\mathrm{CO}_{2}(\mathrm{~g})$ under various pressure and temperature conditions are provided using scanning electron microscopy-energy dispersive spectroscopy (SEM-EDS), $\mathrm{N}_{2}$ gas adsorption method, X-ray diffraction (XRD), and X-ray microtomography (XMT) to develop the $\mathrm{CO}_{2}$ leakage model and lower the uncertainty of the wellbore flow model. 


\subsection{Materials and Methods}

\subsection{High Pressure and Temperature Experiment}

Cement slurry was prepared by mixing Portland cement with water at a water-to-cement ratio of 0.33 (Ash Grove, type II-V) for cement columns with $14 \mathrm{~mm}$ diameter and $90 \mathrm{~mm}$ long or at a water-tocement ratio of 0.38 (Lafarge North America, type I-II) for cement columns with $7 \mathrm{~mm}$ diameter and 20 $\mathrm{mm}$ long. Type II-V cement is comprised of $\mathrm{CaO}(64 \%)$ and $\mathrm{SiO}_{2}(22 \%)$ primarily, as well as $\mathrm{Al}_{2} \mathrm{O}_{3}(3 \%)$ and $\mathrm{Fe}_{2} \mathrm{O}_{3}(4 \%)$, while type I-II cement consists of $\mathrm{CaO}(64 \%)$ and $\mathrm{SiO}_{2}(21 \%)$ primarily, as well as $\mathrm{Al}_{2} \mathrm{O}_{3}$ (4\%), $\mathrm{Fe}_{2} \mathrm{O}_{3}(3 \%)$, and $\mathrm{SO}_{3}(3 \%)$. Cement samples with $14 \mathrm{~mm}$ diameter and $90 \mathrm{~mm}$ long were cast in the form of cylinders by pouring the slurry into a $15 \mathrm{~mL}$ centrifuge tube containing steel coupons or basalt fragments from the Wallula pilot site, while cement samples with $7 \mathrm{~mm}$ diameter and $20 \mathrm{~mm}$ long were placed into a plastic mold without additive, and then cured for 28 days. The hardened cement columns (14 $\mathrm{mm}$ diameter $\times 90 \mathrm{~mm}$ long $)$ were placed in a pressure vessel $(300 \mathrm{~mL}$ size with $64 \mathrm{~mm}$ diameter $\times 102$ $\mathrm{mm}$ depth) ${ }^{1}$ containing $130 \mathrm{~mL}$ of synthetic groundwater (chemical composition in Table 2.1).

Table 2.1. Chemical Composition of Artificial Groundwater

\begin{tabular}{cc}
\hline Element & Concentration $(\mathrm{mg} / \mathrm{L})$ \\
\hline $\mathrm{Na}$ & 40.0 \\
$\mathrm{~K}$ & 15.7 \\
$\mathrm{Ca}$ & 20.9 \\
$\mathrm{Mg}$ & 11.1 \\
$\mathrm{Si}$ & $<0.1$ \\
$\mathrm{Ba}$ & 0.2 \\
$\mathrm{Sr}$ & $<0.1$ \\
$\mathrm{~S}$ & 27.5 \\
\hline
\end{tabular}

In vessels 1-4, the bottom half of each sample was submerged in synthetic groundwater saturated with $\mathrm{CO}_{2}$, while the top half was exposed to supercritical $\mathrm{CO}_{2}$. Vessel 1 and 2, which are duplicate vessels, contained two cement columns, each of which included corroded steel coupons or uncorroded steel coupons. Vessel 3 and 4, which are duplicate vessels, contained three cement columns, which are a pure cement column, a cement column with layered cracks, and a cement column including basalt fragments collected from the Wallula $\mathrm{CO}_{2}(\mathrm{~g})$ sequestration pilot study site in Washington State (Table 2.2). In vessel 5 , a small cement column $(7 \mathrm{~mm}$ diameter $\times 20 \mathrm{~mm}$ long) was completely submerged into $130 \mathrm{~mL}$ synthetic groundwater. The experiment was conducted under pressure of $10 \mathrm{MPa}$ and temperature at $50^{\circ} \mathrm{C}$ to represent the pressure and temperature condition at $\mathrm{CO}_{2}$ injection depth of $1 \mathrm{~km}$ below the surface assuming a geothermal gradient of $30^{\circ} \mathrm{C} / \mathrm{km}$ and a pressure gradient of $10.5 \mathrm{MPa} / \mathrm{km}$. After reaction in vessel 1,2,3, and 4 for 3,20,70,150 days, and in vessel 5 for 3 and 30 days, aqueous samples were collected, measured for $\mathrm{pH}$, and analyzed for major and minor cations using inductively coupled plasmaatomic emission spectroscopy (ICP-AES) after filtration with a $0.45 \mu \mathrm{m}$ membrane filter and acidification to $1 \% \mathrm{HNO}_{3}$. After the reaction for 5 months and 1 month, cement samples were collected from vessels 14 and vessel 5, respectively, then were characterized by SEM-EDS, nitrogen gas adsorption instrument,

\footnotetext{
${ }^{1}$ Parr Instrument Company.
} 
and XMT (see Section 2.5 for detail). Cement columns collected from vessels were cut into slices using a Buehler-IOSMet Low Speed Saw (Model\#11-1280-160) before the analyses.

Table 2.2. Description of Cement Columns for High P-T Experiment

\begin{tabular}{cclc}
\hline Vessel & Sample ID & \multicolumn{1}{c}{ Samples } & Reaction Period \\
\hline 1 & NRAP-3 & Cement with corroded steel & 5 months \\
& NRAP-6 & Cement with uncorroded steel & \\
2 & NRAP-4 & $\begin{array}{l}\text { Cement with corroded steel } \\
\text { NRAP-8 }\end{array}$ & 5 months \\
& NRAP-11 & Cement with uncorroded steel & \\
& NRAP-15 & Cement only & 5 months \\
& NRAP-23 & Cement with basalt & \\
& NRAP-10 & Cement with layered cracks & 5 months \\
& NRAP-16 & Cement only & \\
& NRAP-24 & Cement with basalt & 1 month \\
\hline
\end{tabular}

\subsection{Low Pressure and Temperature Experiment}

A small-diameter cement column sample (Lafarge North America, type I-II; $7 \mathrm{~mm}$ diameter $\times 20 \mathrm{~mm}$ long) cured at water-to-cement ratio of 0.38 for 28 days was placed in a desiccator (Scienceware) and reacted with $5 \% \mathrm{CO}_{2}$ gas (balanced with $95 \% \mathrm{~N}_{2}$ ) flowing at $20 \mathrm{~mL} / \mathrm{min}$ under $0.1 \mathrm{MPa}$ and $20^{\circ} \mathrm{C}$. The gas was purged through the water contained in the bottom of the desiccator to maintain the humidity at $100 \%$. Before and after the reaction for 1 month and 3 months, physical and chemical properties of samples were characterized by SEM-EDS, nitrogen gas adsorption instrument, and XMT (see Section 2.5 for detail).

\subsection{Effective Liquid Permeability Measurement by Pressurized Potassium lodide Injection}

To test the effect of KI (potassium iodide) solution to enhance the contrast, cement columns were prepared by mixing Portland cement (type I-II) with KI solution ( 0 to $20 \mathrm{wt} . \%)$ at cement-to-water ratio of 0.38 ; the sample was then scanned by XMT. KI solution $(20$ or $30 \mathrm{wt} . \%)$ was injected at a pressure of $\sim 9$ pounds per square inch (psi) for 114 hours using $\mathrm{N}_{2}$ gas into a Portland cement column that was inserted into Tygon tubing (12-mm inner diameter) with silicon sealant to prevent leakage. The sample was then scanned by XMT to estimate the advection distance of KI solution through the pores. Using Darcy's law, the effective liquid permeability of a cement column was determined.

\subsection{Porosity and Air Permeability Measurement}

Porosity and air permeability of a Portland cement column (type I/II; $25 \mathrm{~mm}$ diameter $\times 38 \mathrm{~mm}$ long; water/cement ratio $=0.38$ ) were analyzed by Core Laboratories after drying at $115^{\circ} \mathrm{C}$ using Boyle's Law 
technique by measuring grain volume at ambient conditions and pore volume at indicated net confining stresses (NCS). Permeability to air was measured using the steady-state method at indicated NCS.

\subsection{Analytical Methods}

XRD: X-ray diffractograms were collected using a Phillips X'Pert X-ray diffractometer with $\mathrm{Cu}-\mathrm{K} \alpha$ radiation $\mathrm{X}$-ray tube $(\lambda=1.5418 \AA)$ and a graphite monochrometer. The $\mathrm{X}$-ray source is a long-finefocus, ceramic X-ray tube with $\mathrm{Cu}$ anode. Normal operating power is $40 \mathrm{kV}$ or $50 \mathrm{~mA}(2.0 \mathrm{~kW})$. Data were collected from $2-80^{\circ} 2 \theta$ with a scanning step size of $0.05^{\circ}$ and dwell time of 4 seconds. The white precipitates collected after filtration through a $0.45-\mu \mathrm{m}$ membrane filter were mounted in the XRD holder. The electronic scans were processed using JADE® software. ${ }^{2}$ A database published by the Joint Committee on Powder Diffraction Standards International Center for Diffraction Data (Newtown Square, Pennsylvania) was used to identify crystalline phases by comparing standard single-phase patterns to the bulk XRD patterns measured for the sample.

BET Surface Area and BJH Pore Volume: Surface area was determined using the Micrometrics Surface Area Analyzer. ${ }^{3}$ The approach is based on the multipoint BET (Brunauer, Emmet, and Teller) adsorption equation using nitrogen. An uncrushed cement column was placed in a surface area flask and outgassed for a minimum of 3 hours at $150^{\circ} \mathrm{C}$ and at $3 \mu \mathrm{m} \mathrm{Hg}$ to remove physic-sorbed water and volatile organics. After outgassing, the adsorption of nitrogen determines the surface area. To determine the pore size distribution, the method described by BJH (Barrett, Joyner, and Halenda) was used. As the nitrogen is added or removed from the pores using equal step changes in relative pressure, the pressure change represents the volume of pores in that step. Using a thickness relationship, the radius was calculated. The volume of the pore was calculated assuming the pore is a right circular cylinder.

SEM-EDS Analysis: SEM was used to investigate the chemical composition and microstructure of the cement columns. Before SEM analysis, samples were placed in a $105^{\circ} \mathrm{C}$ oven overnight to remove moisture. The oven-dried specimen was then mounted with double-sided carbon tape attached to an aluminum stub. The data were measured using an FEI Quanta 3D FEG instrument. The EDS analysis was conducted using Genesis software from EDAX. The e-beam energy during the analysis was $20 \mathrm{kV}$ at $4 \mathrm{nA}$. For most of the analysis, K-alpha positions were considered for the calculations. The EDS mapping was carried out at $512 \times 400$ pixel resolution with total number of frames of 512. The dwell time during the analysis was $200 \mathrm{~ms}$. The estimation of the atomic ratios was done by considering atomic concentration over the weight concentration. The background noise subtraction of the data was done using the Genesis software before calculations.

X-ray Microdiffraction: The white precipitates on the outside surface of the cement sample were analyzed using a Rigaku D/Max Rapid II microdiffraction system. X-rays were generated (MicroMax 007HF) from a rotating Cr target $(\lambda=2.2910 \AA$ ) and focused through a 300- $\mu$ m diameter collimator directly onto a region of interest identified using the integral video microscope. X-rays of this wavelength usually penetrate much less than $100 \mu \mathrm{m}$ into typical specimens, and so the analysis is dominated by compounds in this surface region. Diffraction data recorded on a two-dimensional image plate were integrated between 10 and $160^{\circ} 2 \theta$ using the manufacturer's software to give powder traces.

\footnotetext{
${ }^{2}$ JADE is a registered trademark of Materials Data Inc., Livermore, California.

${ }^{3}$ Model 2020, Micrometrics In strument Corp., Norcross, Georgia.
} 
The phases present were identified by comparison with library patterns supplied by the International Center for Diffraction Data using JADE v9.3.

X-Ray Microtomography: XMT analysis was conducted using an NSI X-View Digital X-ray Imaging and Computed Tomography system manufactured by North Star Imaging, Inc. Columns were imaged at $98 \mathrm{KeV}$ and $536 \mu \mathrm{A}$, with 1 image per $0.5^{\circ}$ of rotation. Two-dimensional reconstruction and three-dimensional volume rendering were conducted using efx-ct image reconstruction software. Image segmentation and advanced visualization were performed using AVIZO ${ }^{\circledR}$ Fire 6.0 image processing software. ${ }^{4}$ Isosurface and isoline modules were overlaid on an $\mathrm{X}, \mathrm{Y}$, and $\mathrm{Z}$ orthoslice display to visualize differences in $\mathrm{X}$-ray attenuation due to compositional variation within the samples.

\footnotetext{
${ }^{4}$ AVIZO is a registered trademark of Visualization Sciences Group SAS, United States.
} 


\subsection{Results and Discussion}

\subsection{High Pressure and Temperature Experiment}

\subsubsection{Aqueous Chemical Composition Change}

When Portland cement columns $(14 \mathrm{~mm}$ diameter $\times 90 \mathrm{~mm}$ long; $/ \mathrm{c}=0.33)$ with combinations of steel and basalt rock (Table 2.2) were reacted with $\mathrm{CO}_{2}$ in supercritical and dissolved phase under high $\mathrm{P}$ $(10 \mathrm{MPa})$ and $\mathrm{T}\left(50^{\circ} \mathrm{C}\right)$ conditions, dissolved $\mathrm{Na}, \mathrm{K}$, and $\mathrm{Mg}$ increased rapidly from 40, 16, and $11 \mathrm{mg} / \mathrm{L}$ to approximately 100,450 , and $200 \mathrm{mg} / \mathrm{L}$ in vessels $1-4$ after the reaction for 3 days (Figure 3.1). Then $\mathrm{Na}$ and K concentrations varied little in vessel 1, while concentrations increased slightly to 195 and 694 $\mathrm{mg} / \mathrm{L}$ in vessel 2, 190 and $617 \mathrm{mg} / \mathrm{L}$ in vessel 3, and 253 and $959 \mathrm{mg} / \mathrm{L}$ in vessel 4, respectively, for 5 months (Figure 3.1). Dissolved Mg concentration steadily increased over the course of 5 months to 621, 694, 983 and $1050 \mathrm{mg} / \mathrm{L}$ in vessel 1, 2, 3, and 4, respectively. Dissolved Ba concentration varied inconsistently over the course of 5 months, but increased from $0.2 \mathrm{mg} / \mathrm{L}$ to $0.5 \sim 0.7 \mathrm{mg} / \mathrm{L}$ in all vessels at the end of the experiment. Dissolved $\mathrm{Sr}$ was also variable inconsistently but increased from $0.03 \mathrm{mg} / \mathrm{L}$ to $1.69,1.54,0.71$, and $0.91 \mathrm{mg} / \mathrm{L}$ in vessel $1,2,3$, and 4 , respectively, at the end of the experiment.

Change of dissolved S concentration for 5 months was negligible, showing an increase by a factor of $\sim 1.5$ in all vessels. Concentrations of major cations were higher in vessel 3 and 4 than vessel 1 and 2 by a factor of 1.5 2, which could be attributable to a higher number of cement columns in vessel 3 and 4 ( 3 cement columns each) than vessel 1 and 2 ( 2 cement columns each), which resulted in higher solid-tosolution ratio in vessel 3 and 4 than vessel 1 and 2. Dissolution of basalt included in a cement column in vessel 3 and 4 could have also contributed to the increase of dissolved major cations. Dissolved Ca concentration inconsistently varied by 2 orders of magnitude over 5 months, which seems to be affected by neutralization of $\mathrm{pH}$ (6.5 7.5 over 5 months) because of $\mathrm{CO}_{2}(\mathrm{~g})$ degassing immediately after sampling of liquid from high P-T vessels. The $\mathrm{pH}$ neutralization due to $\mathrm{CO}_{2}(\mathrm{~g})$ degassing resulted in the precipitation of calcite in sample vials, which was confirmed by XRD after filtration through a $0.45-\mu \mathrm{m}$ membrane filter (Figure 3.2). Dissolved Na, K, and Mg increased by a factor of 1.5, 2.2, and 3.0, respectively, for 1 month in vessel 5 containing a small-sized Portland cement column $(7 \mathrm{~mm}$ diameter $\times$ $20 \mathrm{~mm}$ long; $\mathrm{w} / \mathrm{c}=0.33$ ) without any additive. The increase of the major cations over 1 month were much lower in vessel 5 than vessel 1-4 probably because of lower solid-to-water ratio in vessel 5 than vessel $1-4$ by a factor of 17 . 

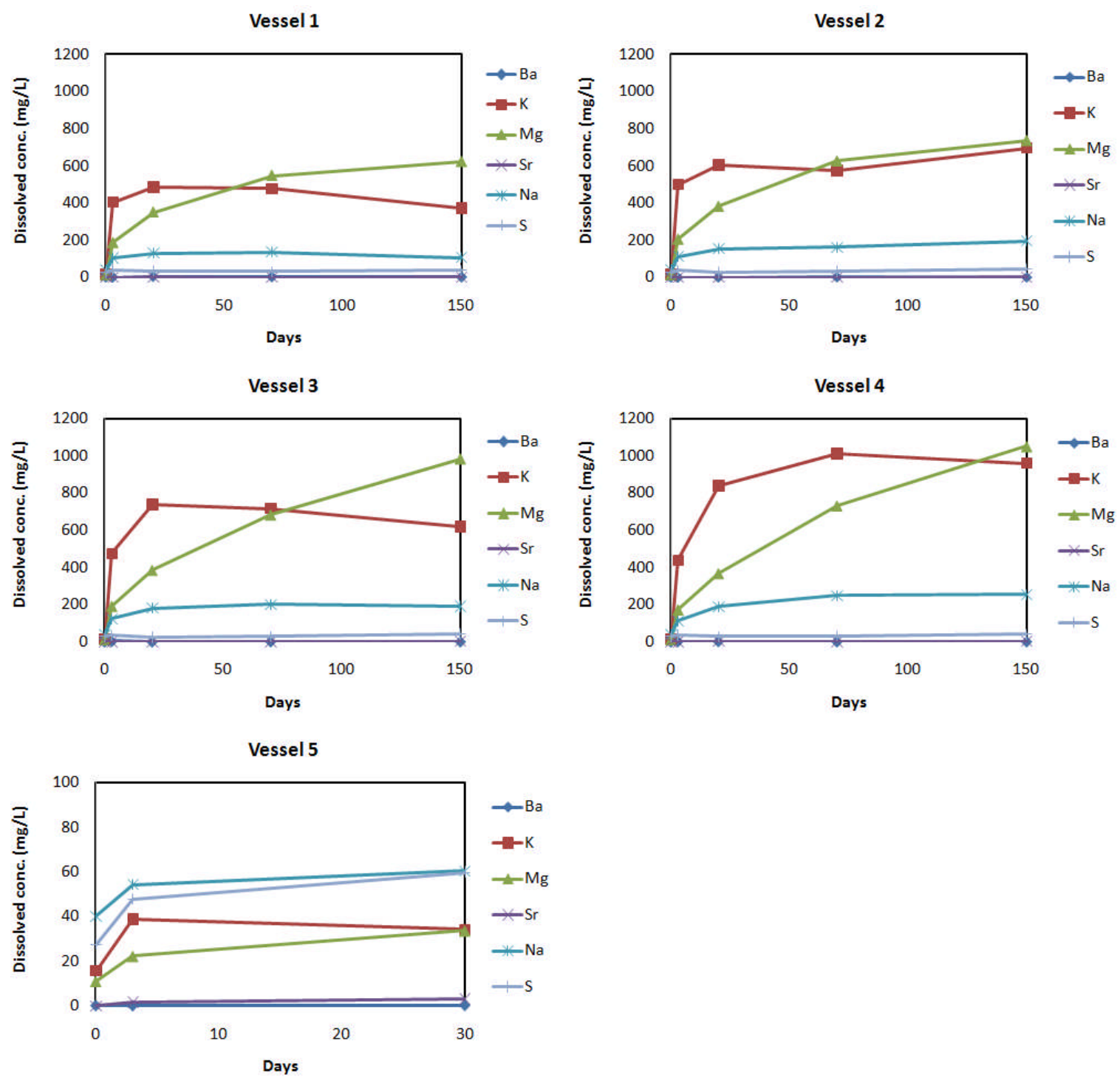

Figure 3.1. Change of Chemical Composition of Artificial Groundwater by $\mathrm{CO}_{2}$ Reaction with Cement in Combination with Steel Coupon and Basalt Under High P-T Condition $\left(10 \mathrm{MPa}+50^{\circ} \mathrm{C}\right)$ for 5 Months (vessel 1-4) and 1 Month (vessel 5). Vessel 1 and 2: artificial groundwater $(130 \mathrm{~mL})+2$ cement columns including corroded or uncorroded steel coupons; vessel 3 and 4: artificial groundwater $(130 \mathrm{~mL})+3$ cement column with layered cracks or basalts or without additive; vessel 5: artificial groundwater $(130 \mathrm{~mL})+1$ cement column without additive. 


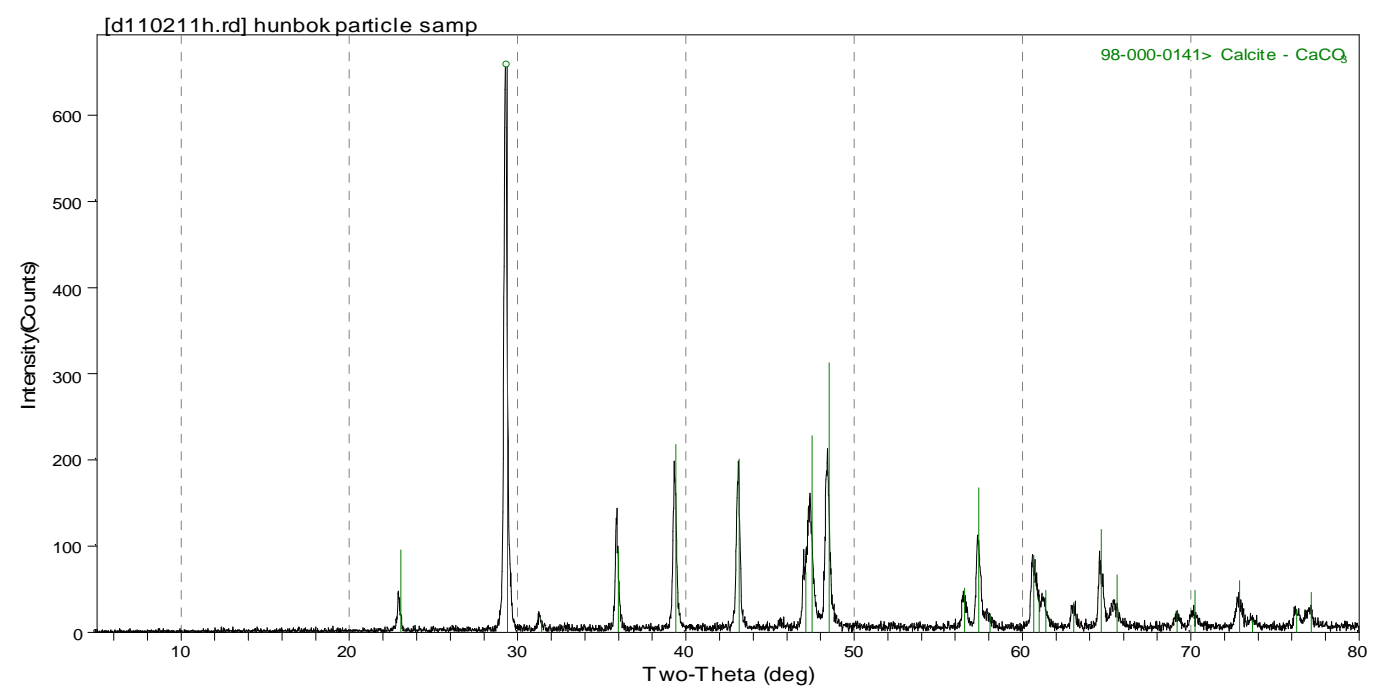

Figure 3.2. XRD Pattern for Precipitates in Aqueous Samples Collected from Four High P-T Vessels by Filtration through a $0.45-\mu \mathrm{m}$ Membrane Filter after $\mathrm{CO}_{2}$ Reaction for 3 and 20 Days. The precipitates are identified as $100 \%$ calcite.

\subsubsection{Solid Chemical Composition and Pore Structure Change}

Cement- $\mathrm{CO}_{2}$ Reaction for 1 Month: After a 1-month reaction with $\mathrm{CO}_{2}$-saturated synthetic groundwater, the outside surface of the cement column showed an orange-brown color (Figure 3.3A). The cross-section of the cement column showed that the inner zone that seems to be unaltered had gray color, while the outer zone that appears to be degraded by $\mathrm{CO}_{2}$ displayed orange-brown color, and the thickness of the outer zone was about $1 \mathrm{~mm}$ (Figure 3.3A). SEM-EDS analysis of the cross-section also indicates the carbonated zone is likely $\sim 1 \mathrm{~mm}$ (Figure 3.3B). The outer carbonation zone (spectrum 4) displays higher $\mathrm{C}(15.4 \%)$ than $\mathrm{Ca}(9.3 \%)$ in atom \%, and the inner carbonation zone (spectrum 3 ) shows similar atom \% for $\mathrm{Ca}(13.0 \%)$ and $\mathrm{C}(10.9 \%)$. The inner zone with spectrum 1 and 2 are less degraded, showing 2-folds higher $\mathrm{Ca}(15 \%)$ than $\mathrm{C}(8 \%)$. 


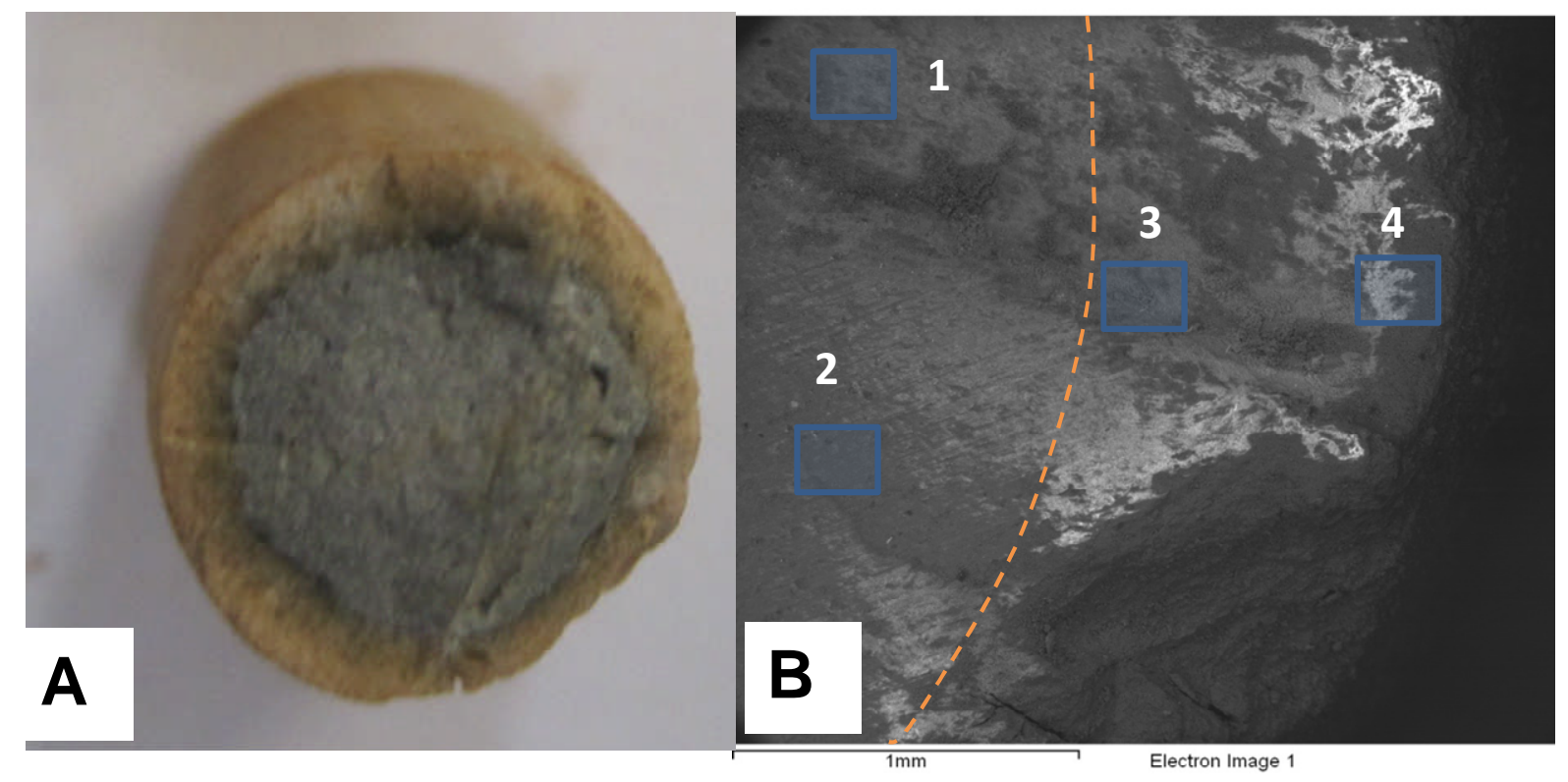

\begin{tabular}{ccccc}
\hline Element & spectrum 1 & spectrum 2 & spectrum 3 & spectrum 4 \\
\hline \hline C K & 8.0 & 8.2 & 10.9 & 15.4 \\
O K & 67.9 & 68.1 & 68.4 & 66.7 \\
Na K & 0.0 & 0.1 & 0.0 & 0.1 \\
Mg K & 0.4 & 0.3 & 0.4 & 0.0 \\
Al K & 1.3 & 1.4 & 1.3 & 1.7 \\
Si K & 6.0 & 5.2 & 5.1 & 6.0 \\
S K & 0.7 & 0.7 & 0.7 & 0.3 \\
K K & 0.0 & 0.0 & 0.0 & 0.0 \\
Ca K & 15.4 & 15.5 & 13.0 & 9.3 \\
Fe K & 0.5 & 0.6 & 0.5 & 0.7 \\
\hline
\end{tabular}

Figure 3.3. (A) The Cross-Section of a Cement Column (NRAP cement-2; $7 \mathrm{~mm} \mathrm{D} \times 20 \mathrm{~mm} \mathrm{~L}$ ) Reacted with $\mathrm{CO}_{2}$-Saturated Synthetic Groundwater; (B) SEM Image of the Cross-Section of the Cement Column with the Position of EDS Analysis with a Dashed Line Indicating Approximate Degradation Zone; (C) Table of SEM-EDS Analyses (atom \%) for Four Positions Indicated in the SEM Image

The SEM images show the outside surface of degraded cement is porous and fractured as the result of carbonic acid exposure (Figure 3.4). The BJH pore volume increased from 0.030 to $0.113 \mathrm{~cm}^{3} / \mathrm{g}$, while the BET surface area increased from 9.0 to $85.6 \mathrm{~m}^{2} / \mathrm{g}$ (Table 3.1). Given the initial total porosity of a duplicate cement column with the same water-to-cement ratio is $31 \%$, such an increase in BJH pore volume can result in the increase of porosity up to $45 \%$. However, note the BJH pore volume measured for noncrushed cement column is likely to represent the pore structure mostly near the outside surface of cement column, not bulk pore structure due to limited diffusion of $\mathrm{N}_{2}$ gas through nano-sized pores $(<100 \mathrm{~nm})$ of cement matrix during the measurement (Figure 3.4). 

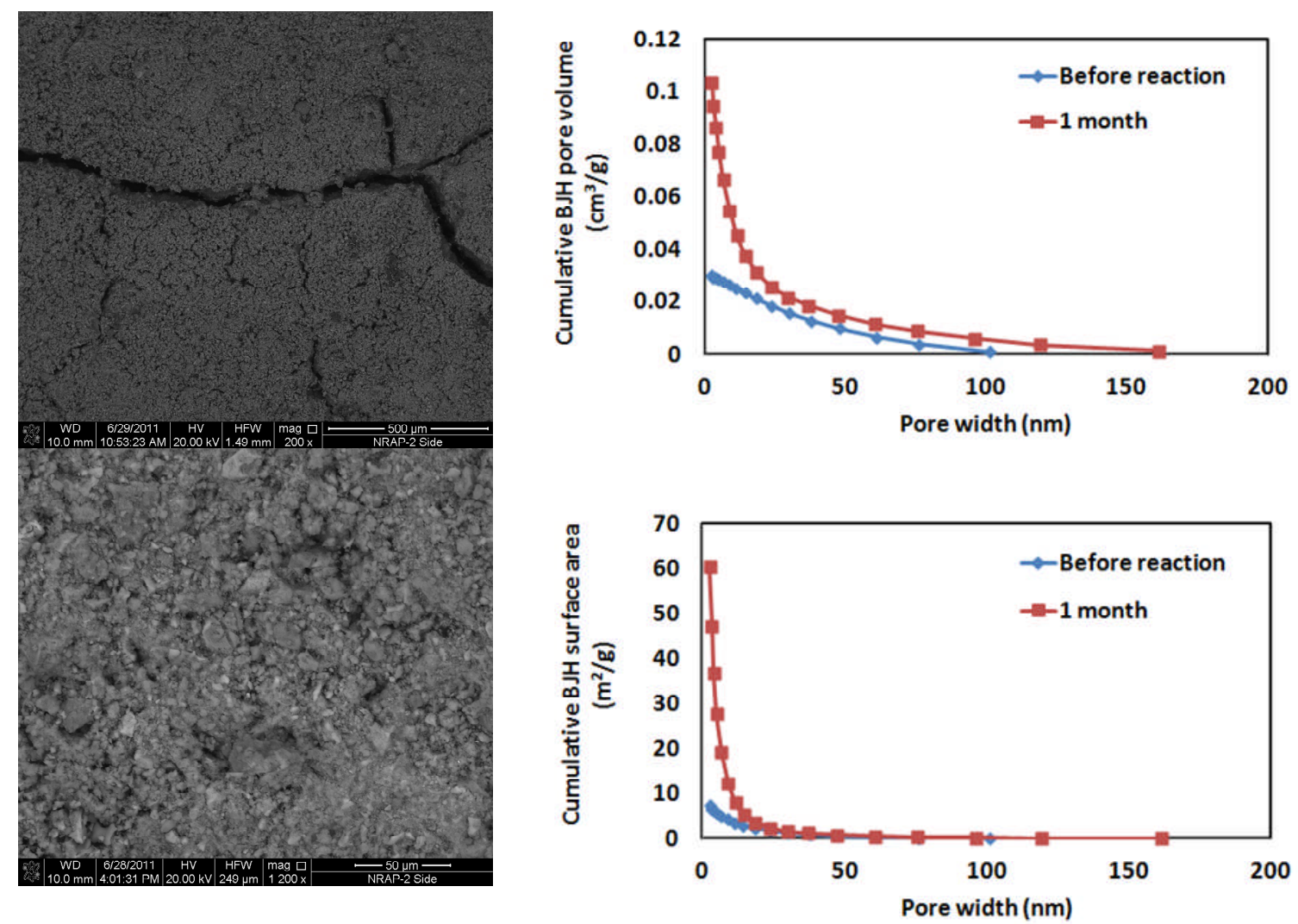

Figure 3.4. SEM-EDS Image of the Outside Surface of NRAP Cement-2 Showing Cracks and Pores After Reaction with $\mathrm{CO}_{2}$-Saturated Synthetic Groundwater Under High P-T For 1 Month (left) and Cumulative BJH Pore Volume and BJH Surface Area for NRAP Cement-2 Before and After the Reaction (right)

Table 3.1. BJH Pore Volume and BET Surface Area Change by $\mathrm{CO}_{2}$ for 1 Month and 3 Months at Low and High P-T Conditions

\begin{tabular}{ccccccc}
\hline & \multicolumn{3}{c}{$\begin{array}{c}\text { BJH Pore Volume } \\
\left(\mathrm{cm}^{3} / \mathrm{g}\right)\end{array}$} & & \multicolumn{3}{c}{$\begin{array}{c}\text { BET Surface Area } \\
\left(\mathrm{m}^{2} \mathrm{~g}\right)\end{array}$} \\
\cline { 2 - 7 } P-T & 0 day & 1 month & 3 months & 0 day & 1 month & 3 months \\
\hline Low & 0.033 & 0.013 & 0.005 & 8.03 & 3.92 & 2.43 \\
High & 0.030 & 0.113 & - & 8.98 & 85.64 & - \\
\hline
\end{tabular}

Based on the BJH pore volume and surface area curves (Figure 3.4), pore volume and surface area increases after $\mathrm{CO}_{2}$ reaction for 1 month are attributed mainly to the significant increase of nano-sized pores $(<20 \mathrm{~nm})$. Together, these data indicate that dissolution reaction of $\mathrm{Ca}(\mathrm{OH})_{2}$ was more dominant than calcite precipitation in cement matrix during an 1-month reaction with $\mathrm{CO}_{2}$ saturated water at high $\mathrm{P}$ $\mathrm{T}$. 
XMT images display a distinct zone of cement degradation by brightness contrast between degraded and nondegraded zones, which results from density change of cement matrix by $\mathrm{CO}_{2}$ reaction because the linear attenuation coefficient of X-ray depends on the density of a material (Wong and Chau 2005;

Kutchko et al. 2009). The approximate depth of cement degradation was estimated based on XMT image of vertical and horizontal cross-sections of cement columns. Two zones characterized with different brightness were identified from XMT images of cement columns reacted with $\mathrm{CO}_{2}$ saturated water at high P-T for 1 month (Figure 3.5C and Figure 3.5D), whereas no obvious brightness contrast is observed from the cement column prior to $\mathrm{CO}_{2}$ reaction (Figure 3.5A and Figure 3.5B). After an 1-month reaction, the outer layer ( $\sim 1 \mathrm{~mm}$ thick) of the cement column appears significantly darker than the center of the cement column. This is attributed to density decrease from initial bulk density of $\sim 2.0 \mathrm{~g} / \mathrm{mL}$, which probably results from dominant dissolution of $\mathrm{Ca}(\mathrm{OH})_{2}$ with little calcite precipitation for 1 month. Such a dominant dissolution reaction over calcite precipitation in cement matrix is likely to lead to increase in porosity as well as permeability, causing higher risk of $\mathrm{CO}_{2}$ leakage.
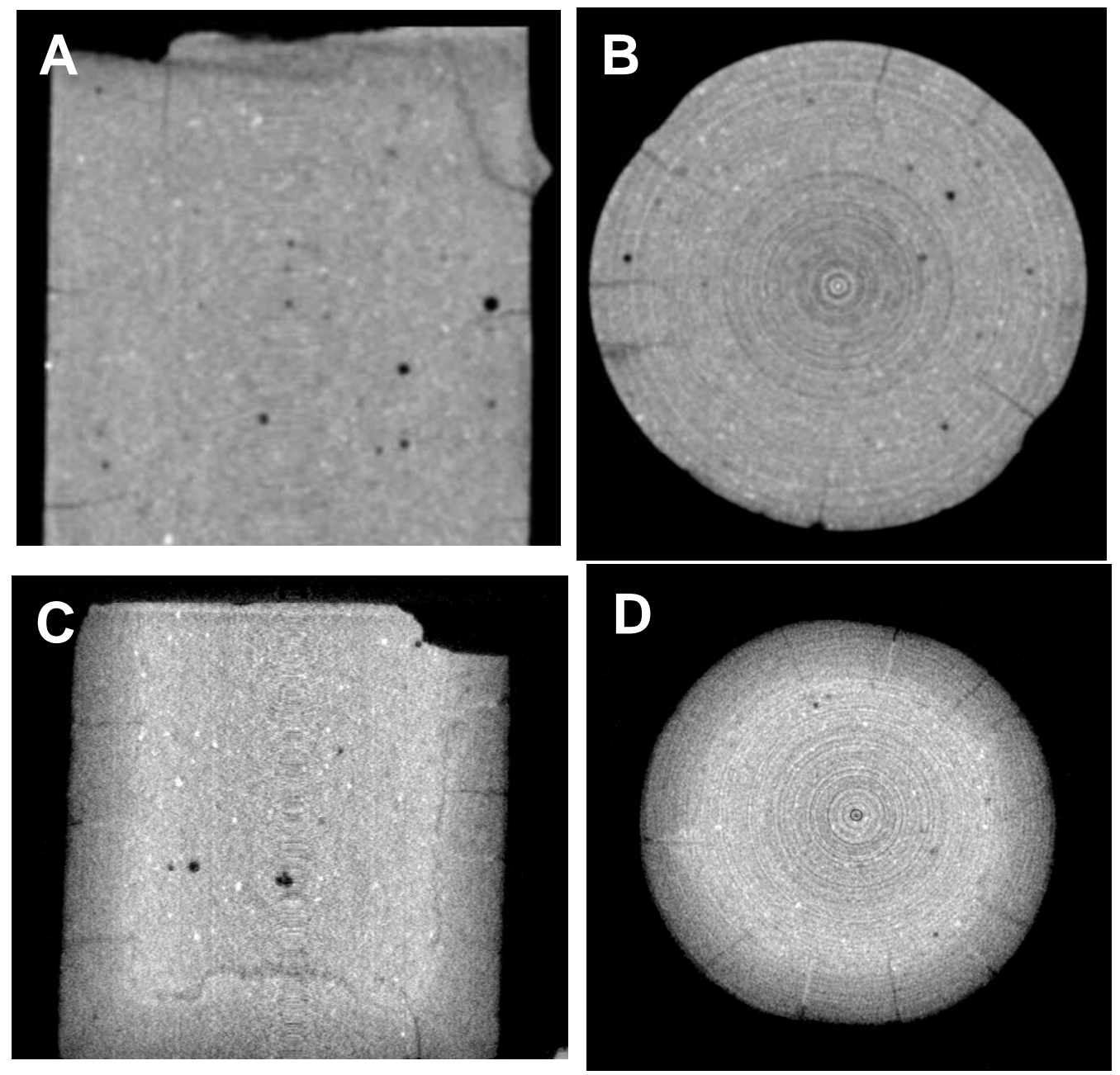

Figure 3.5. XMT Images of a Small-sized Cement Column in Vessel 5 before A) Vertical Cross-section; B) Horizontal Cross-section; and after C) Vertical cross-section; D) Horizontal cross-section Reaction with $\mathrm{CO}_{2}$ Saturated Synthetic Groundwater for 1 Month 
Cement- $\mathrm{CO}_{2}$ Reaction for 5 Months: After the reaction with $\mathrm{CO}_{2}$ for 5 months, the bottom half of the cement columns that were reacted with $\mathrm{CO}_{2}$ saturated synthetic groundwater showed a distinct orange or brown color (Figure 3.6 and Figure 3.7), while the top half of the cement columns that were exposed to supercritical $\mathrm{CO}_{2}$ was less obvious in color change. White-colored calcite precipitates were commonly observed on the outside surface of the bottom half of cement columns. In general, the cross-section of cement columns shows a more extensive degradation by $\mathrm{CO}_{2}$, which is indicated by the orange-colored zone, in the bottom half of cement columns that was reacted with $\mathrm{CO}_{2}$-saturated synthetic groundwater (Figure 3.8B) than the top half of cement columns that was reacted with supercritical $\mathrm{CO}_{2}$ (Figure 3.8A).

Energy dispersive spectroscopy (EDS) data of the cross-section of cement columns (NRAP-3, 6, and 15) consistently indicate there are distinctive zones characterized by the change of atom $\%$ in $\mathrm{Ca}$ and $\mathrm{C}$ (Figure 3.9). The nondegraded (or less degraded) zone of cement cross-section shows higher Ca than $\mathrm{C}$ in atom $\%$ usually by a factor of $2 \sim 3$. The nondegraded center of NRAP-3 shows Ca of $23 \%$ and $\mathrm{C}$ of $7 \%$ in atom \%. The degraded zone consists of two distinct zones (Figure 3.9); an outer zone with higher $\mathrm{C}$ atom $\%$ than $\mathrm{Ca}$ atom $\%$ and an inner zone with similar $\mathrm{Ca}$ and $\mathrm{C}$ atom $\%$. The $\mathrm{Ca} / \mathrm{C}$ atom $\%$ less than 1.0 in the outer degraded zone seems to result from $\mathrm{Ca}(\mathrm{OH})_{2}$ and calcite dissolution, as well as adsorption of diffused carbon on the cement matrix (Haselbach and $\mathrm{Ma} 2008$ ), while $\mathrm{Ca} / \mathrm{C}$ atom $\% \approx 1$ in the inner degraded zone is likely attributed to the precipitation of calcite in the cement matrix with negligible carbon adsorption. Decrease of $\mathrm{Ca}$ atom $\%$ and increase of $\mathrm{C}$ atom $\%$ from the inner zone to outer zone is also evident from EDS mapping (Figure 3.10 and Figure 3.11). An EDS line scan for NRAP-6 cement column shows an obvious increase in $\mathrm{Ca}$ atom $\%$ and decrease in $\mathrm{C}$ atom $\%$ along a line from the outer boundary to the inner zone of the cross-section of the cement column, which resulted in an increase of $\mathrm{Ca} / \mathrm{C}$ atom $\%$ ratio toward the center (Figure 3.11C). NRAP-15 cement column (without additives) showed the thin outermost layer with growth of large calcite crystals (approximately $100 \mu \mathrm{m}$ size) (Figure 3.9). From SEM images of the cross-section for the NRAP-15 cement column, it is also notable the degraded cement surface next to the layer of large calcite crystals is highly porous and fractured (Figure 3.9), which is similar to the outside surface of degraded cement reacted with $\mathrm{CO}_{2}$-saturated water for 1 month at high P-T (Figure 3.4). Such pores and fractures of carbonated cement seem to result from the bicarbonation process, which is the dissolution of calcite by carbonic acid exposure. Subsequently, the remaining C-S-H paste is converted to amorphous silica gel, which lacks structure (Kutchko et al. 2007). The increasing number of bright dots in the EDS mapping for $\mathrm{Si}$ in the outer carbonated zone seems to indicate the enrichment of amorphous silica (Figure 3.10 and Figure 3.11). As a result, porosity and permeability of the cement column can increase due to the porous outer degraded zone, although calcite precipitation in the inner degraded zone $(\mathrm{Ca}$ atom $\%=\mathrm{C}$ atom $\%)$ can reduce the porosity and permeability of the cement column. Unlike the cement column reacted with $\mathrm{CO}_{2}$-saturated synthetic groundwater, the cement column exposed to supercritical $\mathrm{CO}_{2}$ does not show any notable zone by EDS mapping (Figure 3.10) perhaps because of slower penetration of supercritical $\mathrm{CO}_{2}$ likely due to lack of water to diffuse ions out of the cement matrix (Kutchko et al. 2008). 


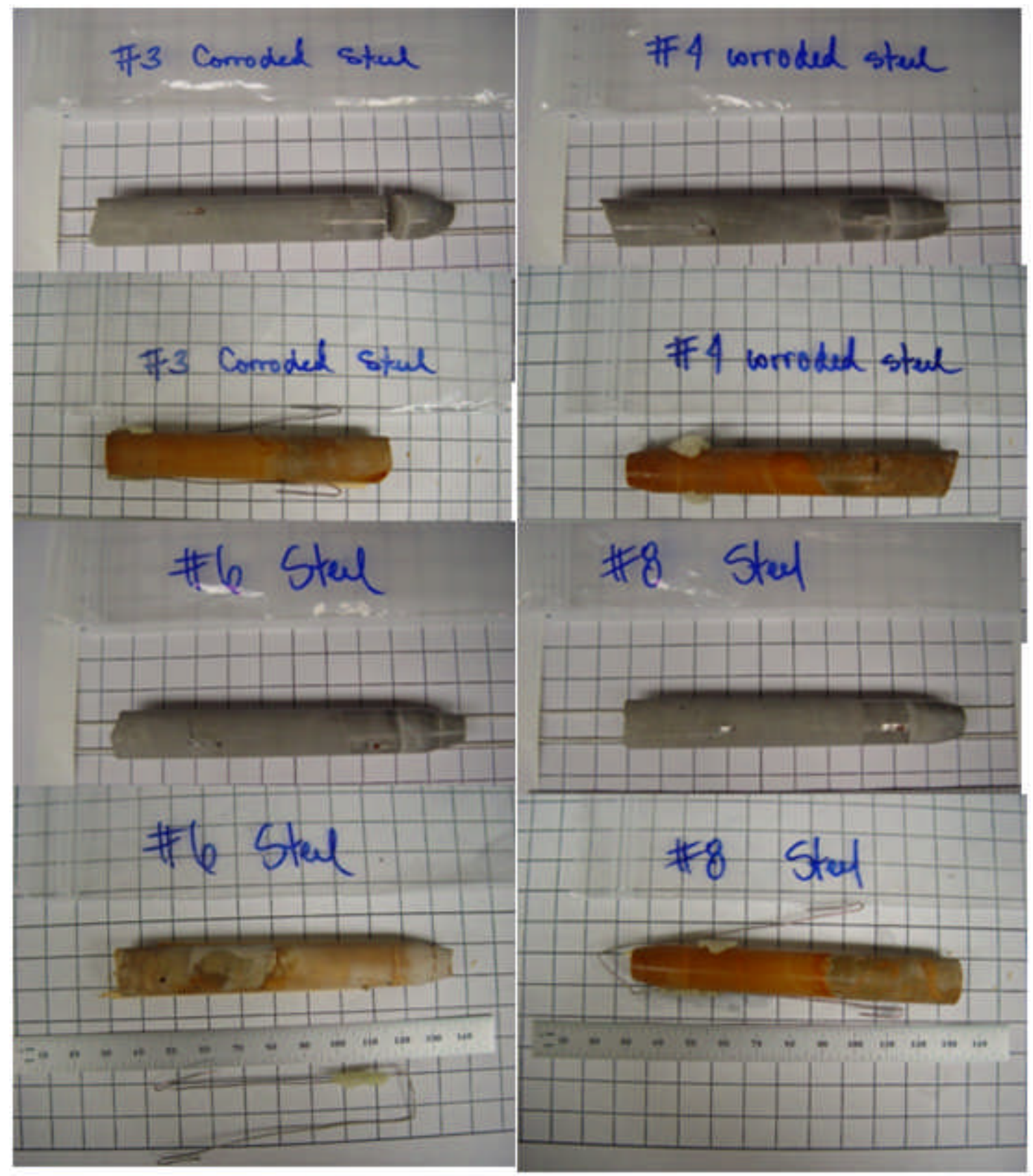

Figure 3.6. Photos of Cement Columns Before (top) and After (bottom) $\mathrm{CO}_{2}$ Reaction Under High P-T in Vessels 1 (cement column \#3 and 6) and 2 (cement column \#4 and 8) 

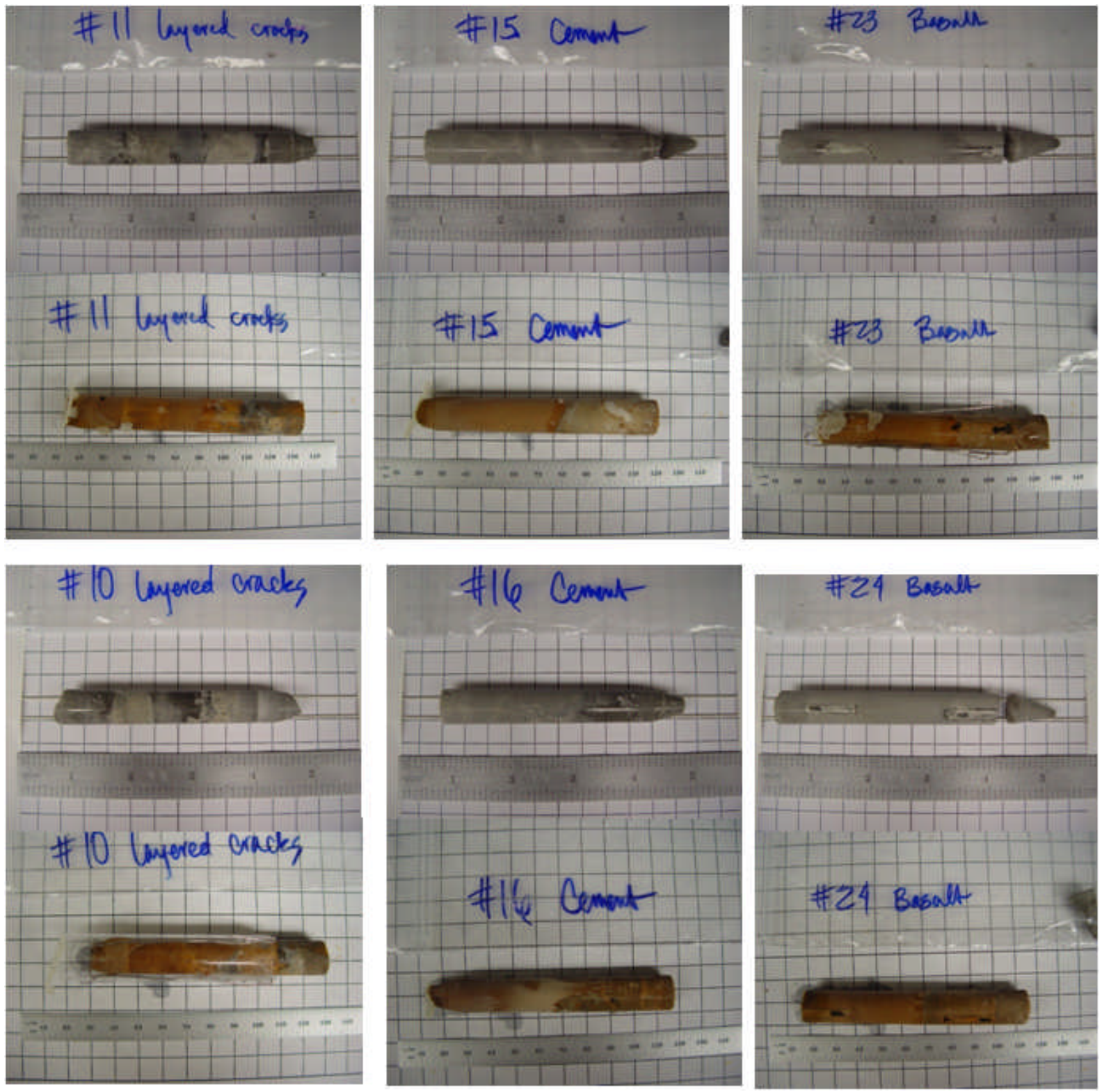

Figure 3.7. Photos of Cement Columns Before (top) and After (bottom) $\mathrm{CO}_{2}$ Reaction Under High P-T in Vessels 3 (cement column \#11, 15, and 23) and 4 (cement column \#10, 16, and 24) 


\section{A. Portland Cement Samples Exposed to Supercritical $\mathrm{CO}_{2}$}
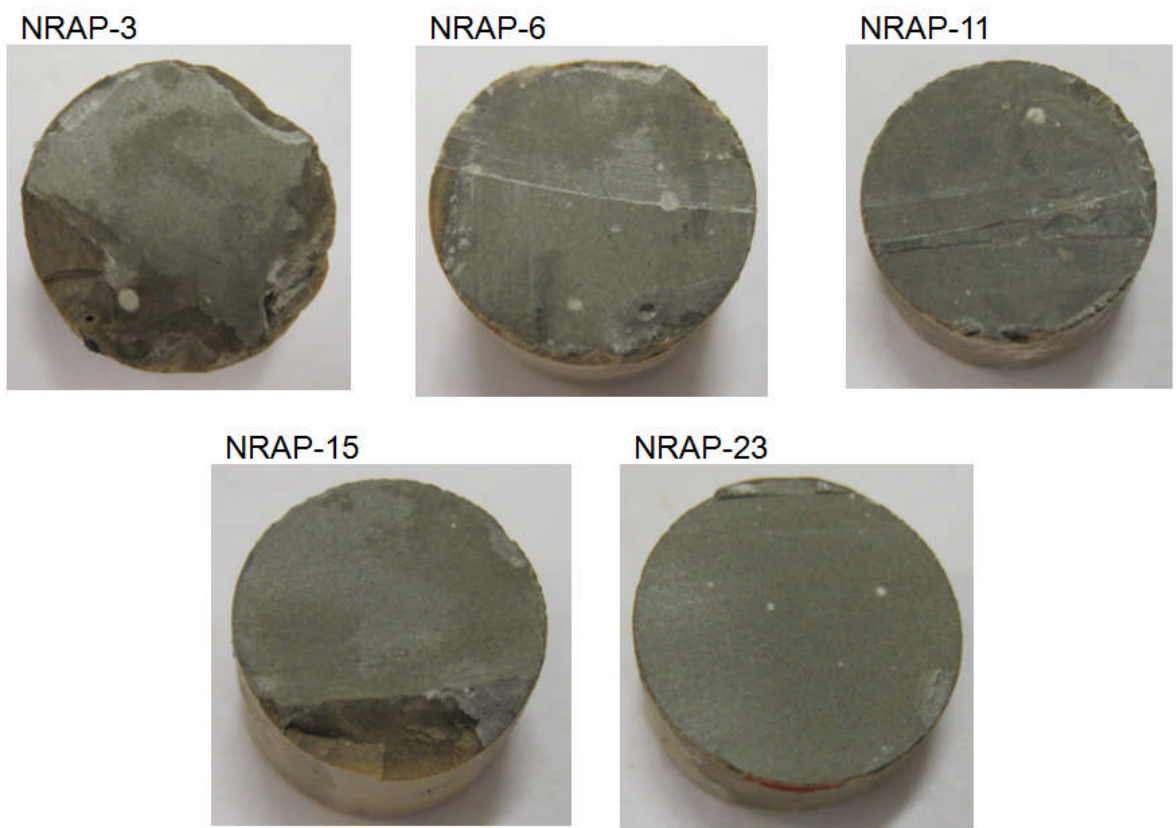

B. Portland Cement Samples Reacted with $\mathrm{CO}_{2}$-Saturated Synthetic Groundwater
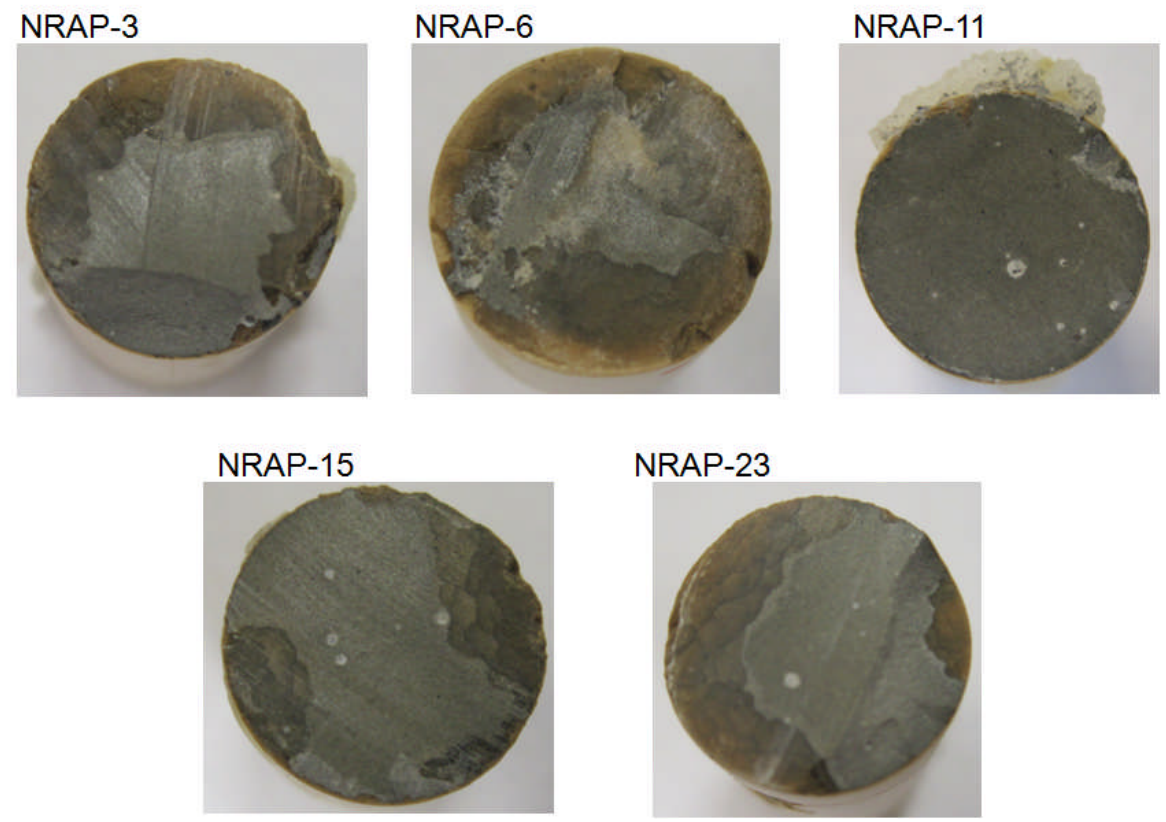

Figure 3.8. The Cross-Section of Cement Columns Reacted with Supercritical $\mathrm{CO}_{2}(\mathrm{~A})$ and $\mathrm{CO}_{2}$-Saturated Synthetic Groundwater (B) 


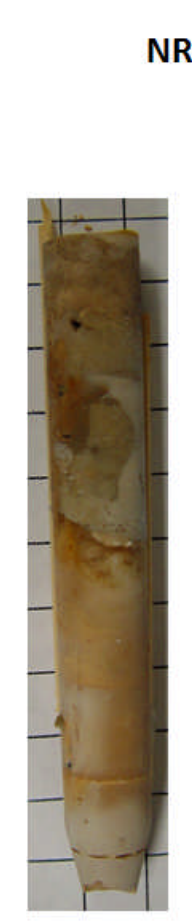

NRAP-3
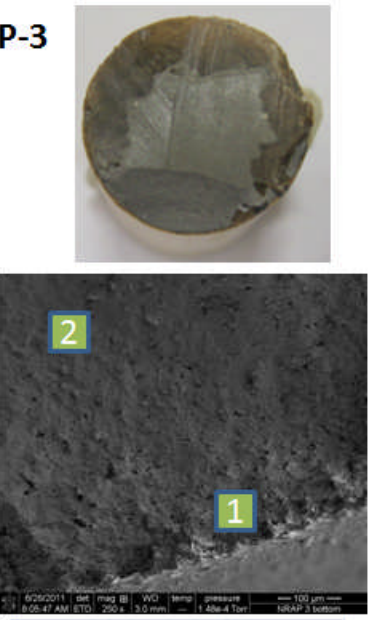

Element Spectrum 1 Spectrum 2

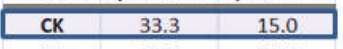

OK

\begin{tabular}{l|l|l} 
MgK & 0.3 & 0.4 \\
\hline
\end{tabular}

$\begin{array}{llll}\text { AIK } & 1.2 & 1.5\end{array}$

\begin{tabular}{l|l|l} 
SiK & 5.9 & 6.6
\end{tabular}

\begin{tabular}{l|l|l|}
\hline SK & 0.1 & 0.1 \\
\hline
\end{tabular}

\begin{tabular}{|l|l|l|}
\hline KK & 0.5 & 0.3 \\
\hline
\end{tabular}

\begin{tabular}{|ccc|}
\hline CaK & 7.4 & 14.6 \\
\hline FeK & 0.7 & 0.9 \\
\hline
\end{tabular}

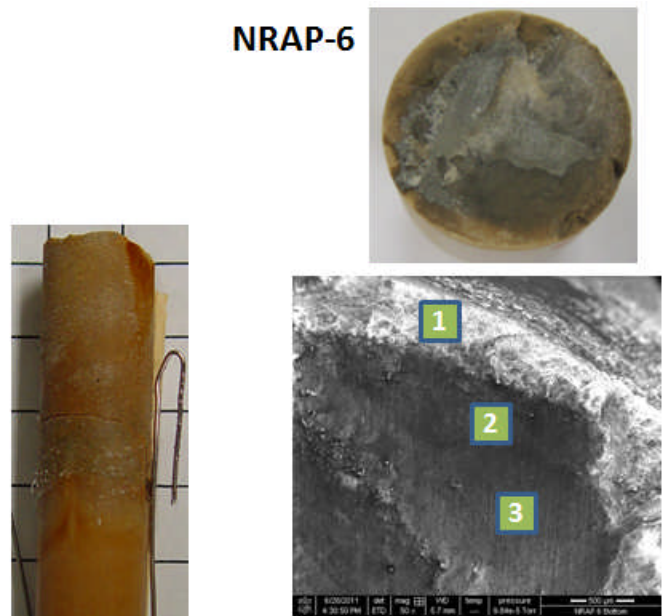

\begin{tabular}{|c|c|c|c|}
\hline Element & Spectrum 1 & Spectrum 2 & Spectrum 3 \\
\hline CK & 22.1 & 16.5 & 9.1 \\
\hline OK & 54.4 & 57.2 & 59.6 \\
\hline MgK & 0.4 & 1.2 & 2.5 \\
\hline AlK & 1.4 & 1.4 & 1.8 \\
\hline sik & 7.5 & 7.3 & 8.0 \\
\hline SK & 0.3 & 0.6 & 1.1 \\
\hline KK & 0.3 & 0.2 & 0.1 \\
\hline CaK & 12.7 & 14.9 & 17.0 \\
\hline
\end{tabular}

NRAP-15
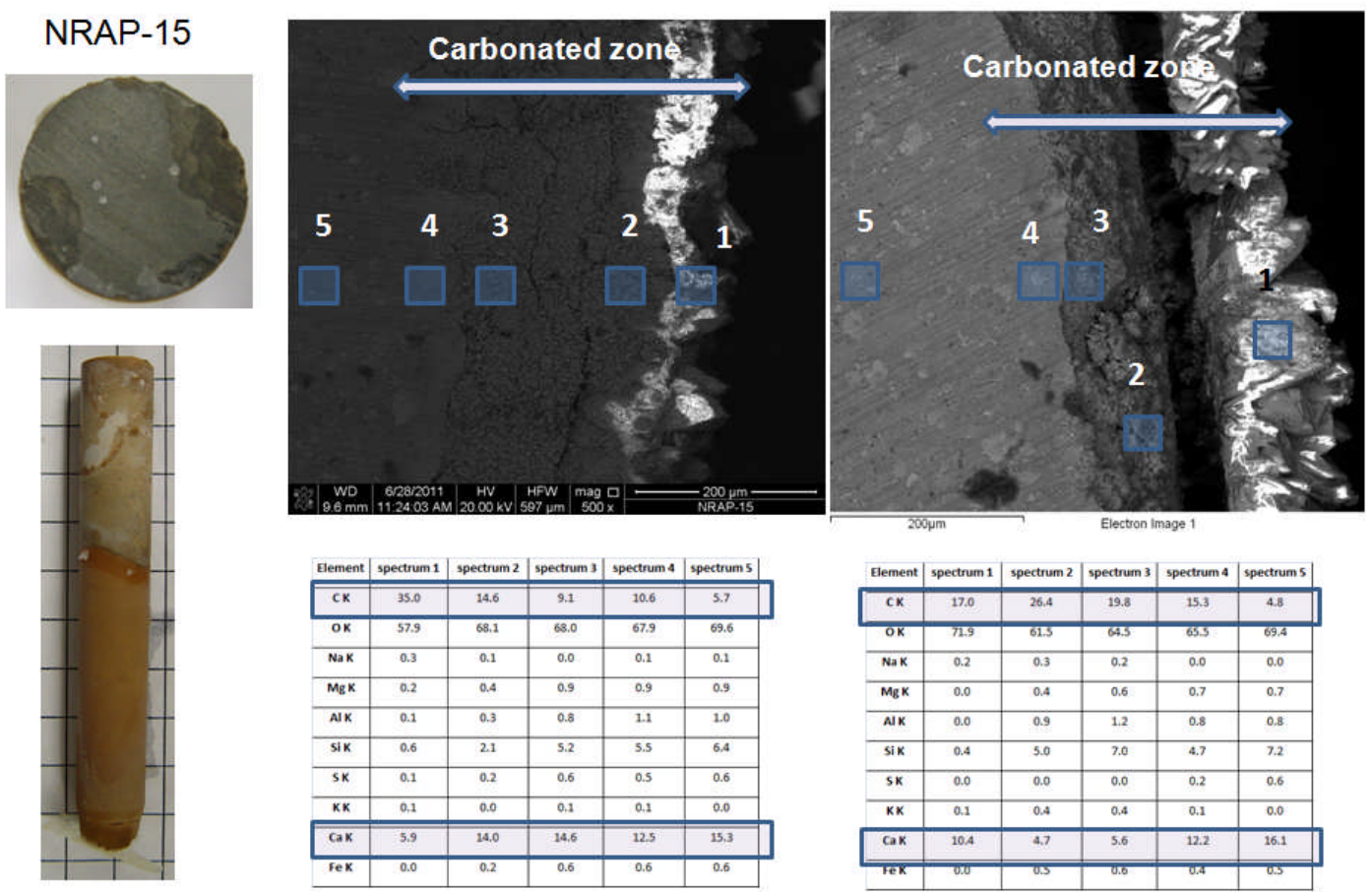

Figure 3.9. SEM Images of the Cross-Section of Cement Columns (NRAP-3, 6, and 15) and EDS Analyses Showing Spatial Change of Cement Chemical Composition 

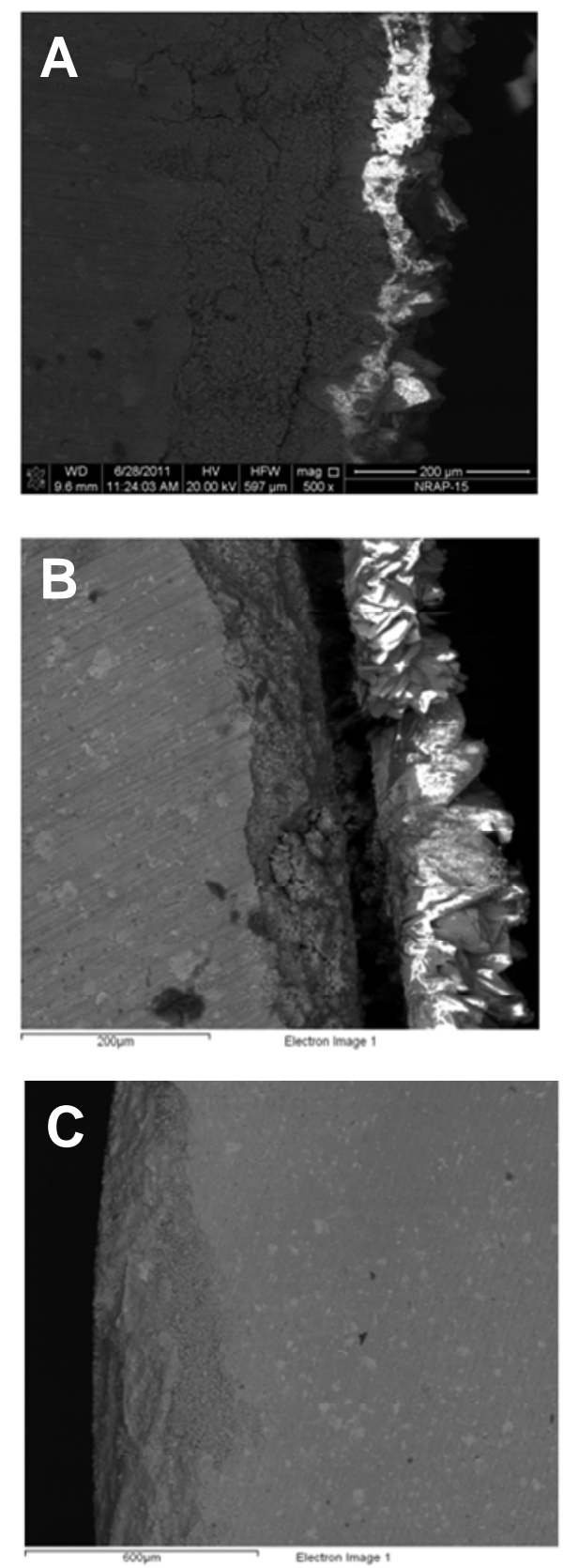
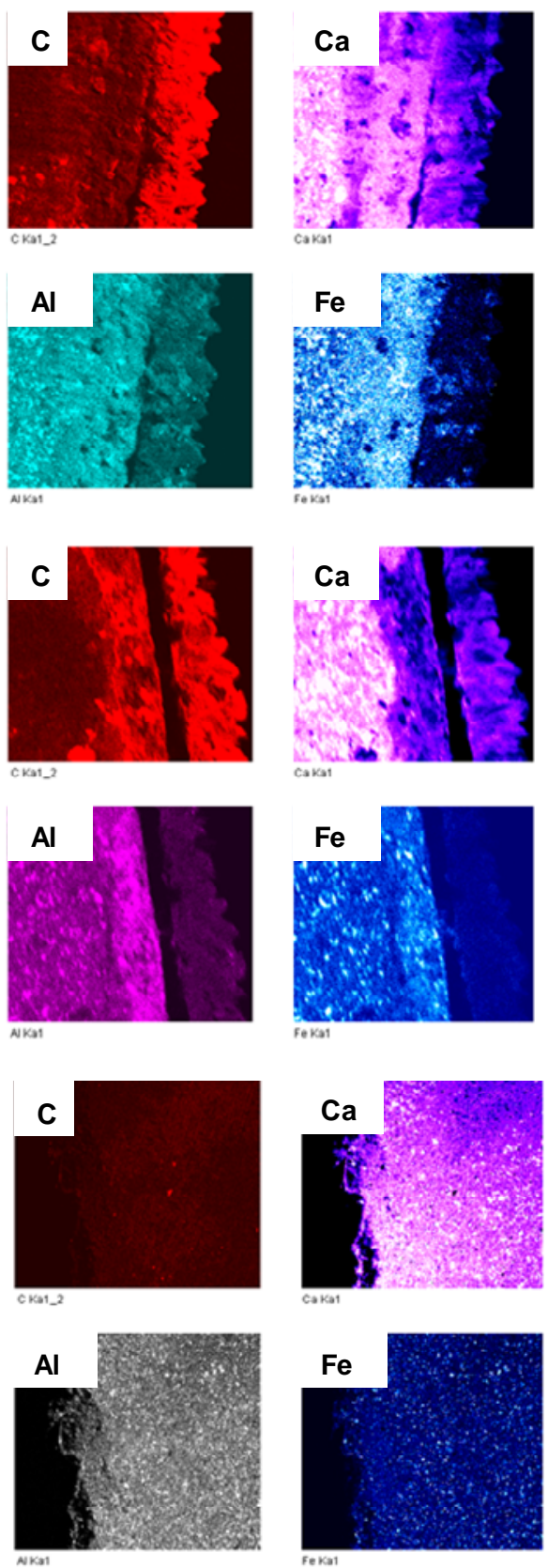
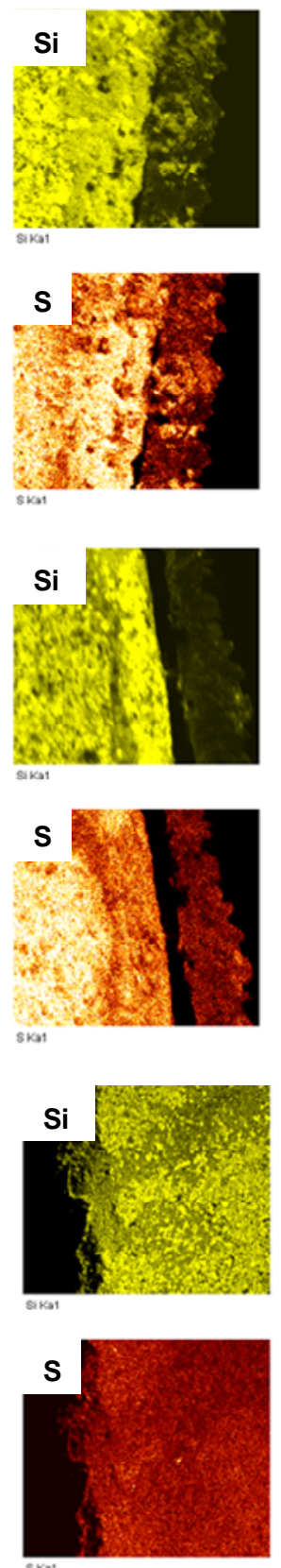

Figure 3.10. SEM Images and EDS Mapping for the NRAP-15 Cement Column Reacted with $\mathrm{CO}_{2}$-Saturated Synthetic Groundwater (A and B) and with Supercritical $\mathrm{CO}_{2}(\mathrm{C})$ 

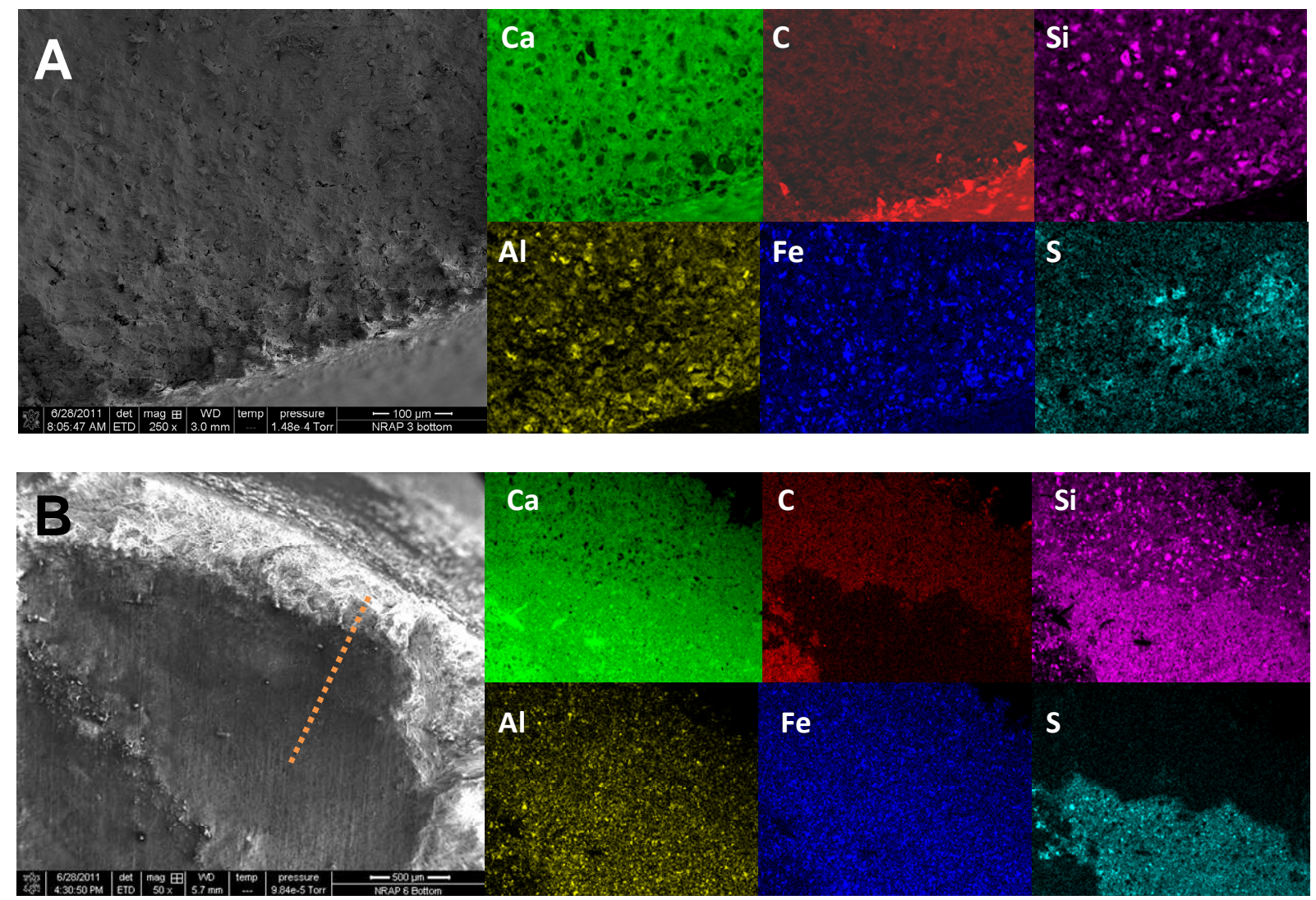

C
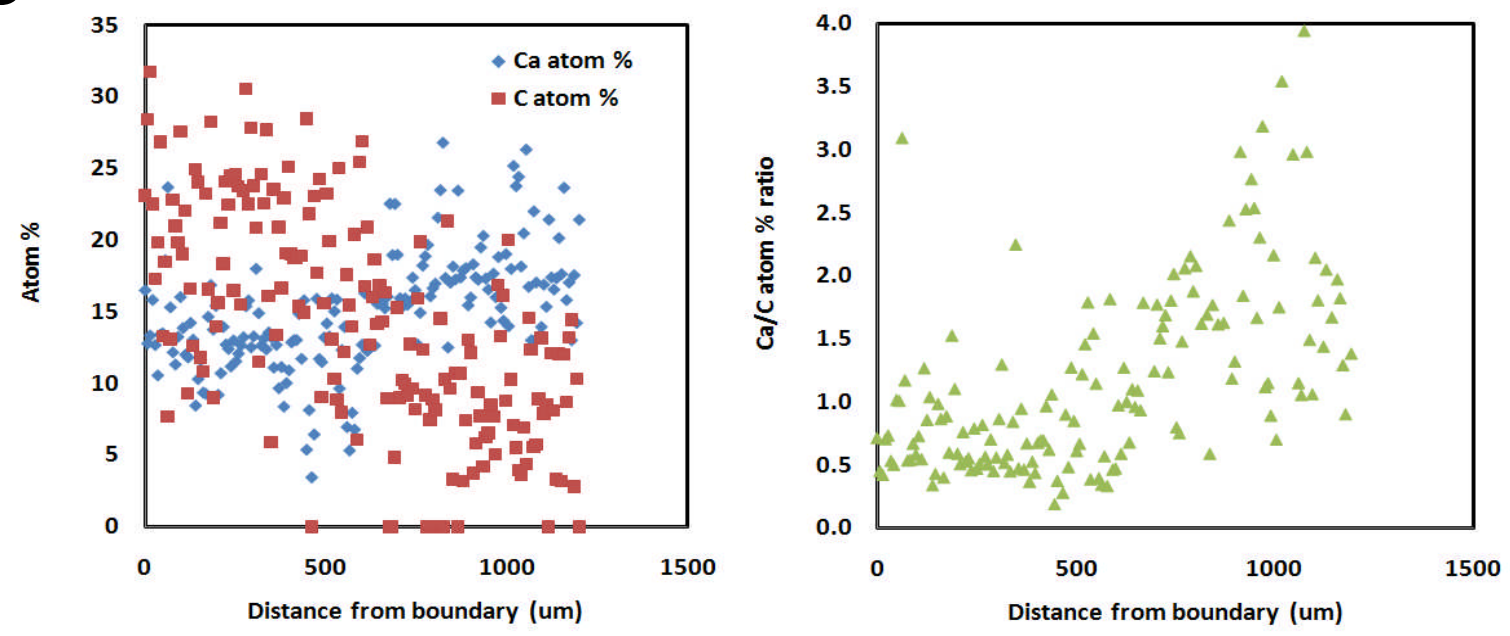

Figure 3.11. SEM Images and EDS Mapping for NRAP-3 (A) and NRAP-6 Cement Columns (B), and Atom \% of $\mathrm{Ca}$ and $\mathrm{C}$ as well as $\mathrm{Ca} / \mathrm{C}$ atom \% Ratio by Line Scan for NRAP-6 (C) 
After a 5-month reaction of a pure cement column (NRAP-16) with $\mathrm{CO}_{2}$, the degraded outer layer is brighter than the nondegraded cement matrix at the center in the XMT images for both the top and bottom half of the cement column (Figure 3.12), which is attributed to precipitation of calcite with a density of $2.7 \mathrm{~g} / \mathrm{mL}$ in cement matrix, resulting in higher bulk density of the degraded outer zone than nondegraded center with bulk density of $\sim 2.1 \mathrm{~g} / \mathrm{mL}$. However, the XMT image was unable to distinguish an inner degraded zone dominated with calcite precipitation from an outer degraded zone dominated with calcite dissolution and amorphous silica enrichment probably because the density of silica $(2.65 \mathrm{~g} / \mathrm{mL})$ is very similar to density of calcite. Between the nondegraded center and degraded outer zone, there appears to be a thin dark layer, which is darker than the nondegraded center or degraded outer zone (Figure 3.12). This seems to be the degradation front with low density due to dominant dissolution of $\mathrm{Ca}(\mathrm{OH})_{2}$, which likely corresponds to Zone 1 with $\mathrm{Ca}(\mathrm{OH})_{2}$ depletion in Kutchko et al. $(2007,2008)$.

NRAP-16 top

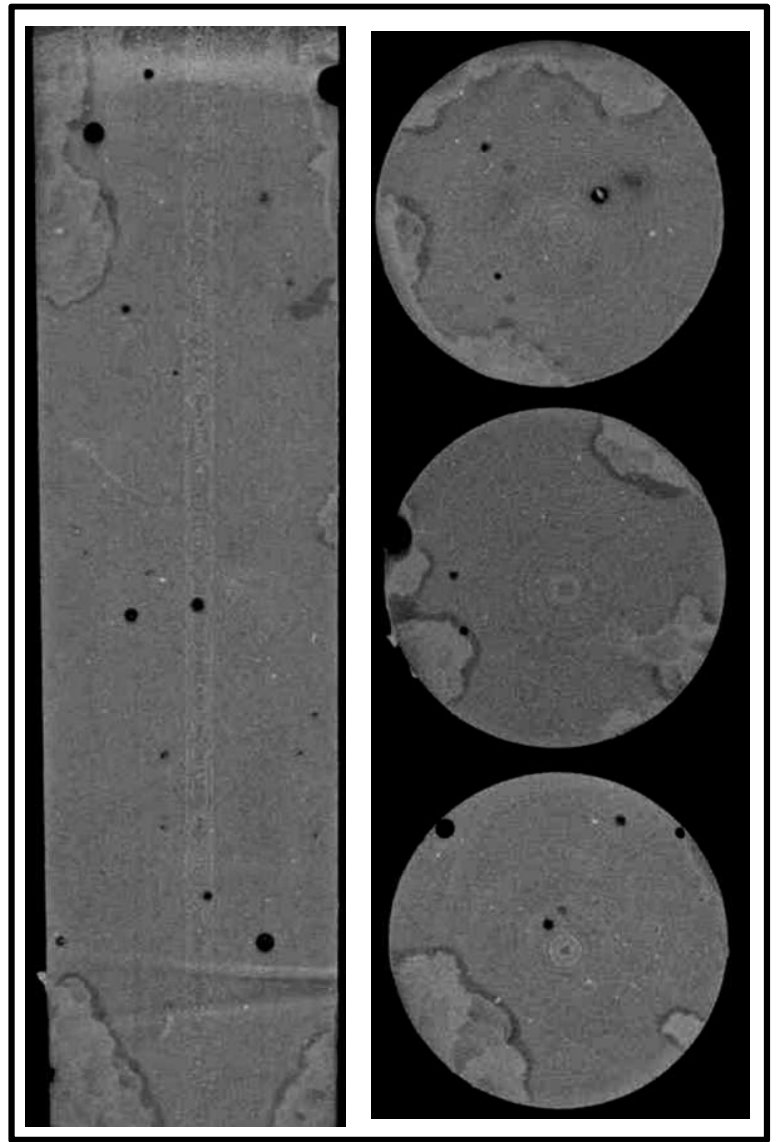

NRAP-16 bottom

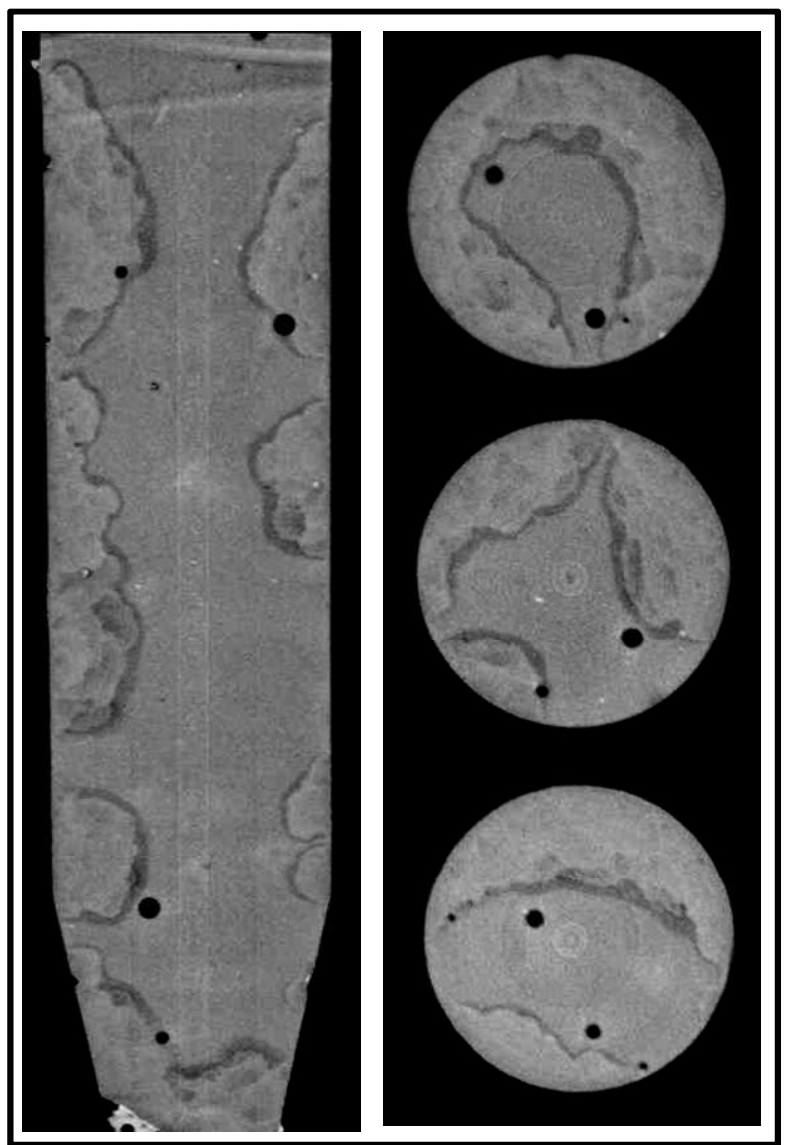

Figure 3.12. XMT Images of Cement Column (NRAP-16) after Reaction with Supercritical $\mathrm{CO}_{2}$ (left) and $\mathrm{CO}_{2}$ (right) Saturated Water for 5 Months 
Based on XMT images, the approximate degradation depth by $\mathrm{CO}_{2}$ saturated water is $\sim 3.5 \mathrm{~mm}$ for a cement column with water-to-cement ratio of 0.33 after a 5-month reaction (Figure 3.12), while $\sim 1 \mathrm{~mm}$ for a cement column with water-to-cement ratio of 0.38 after an 1-month reaction (Figure 3.5). Slower degradation rates ( $0.7 \mathrm{~mm}$ per month) for cement columns with water-to-cement ratio of 0.33 after a 5-month reaction than for cement columns ( $1 \mathrm{~mm}$ per month) with water-to-cement ratio of 0.38 after a 1-month reaction is attributed to slower $\mathrm{Ca}$ and carbonate diffusion through the pores of cement matrix with lower water-to-cement ratio (Haga et al. 2005), as well as slower degradation rates with increasing reaction times due to the change of cement pore structure (Kutchko et al. 2008).

Cement degradation slows down as a function of $\mathrm{CO}_{2}$ reaction time because of increasing precipitation of calcite in cement matrix, which reduces porosity and permeability of cement matrix. In contrast, cement column exposed to supercritical $\mathrm{CO}_{2}$ for 5 months showed little change in brightness contrast (Figure 3.12), suggesting the degradation depth by supercritical $\mathrm{CO}_{2}$ is shallow, which is consistent with Kutchko et al. (2008) showing that the cement exposed to supercritical $\mathrm{CO}_{2}$ produced a slow penetration of supercritical $\mathrm{CO}_{2}$ with no individual distinct alteration zones due to a lack of water to diffuse ions out of the cement matrix. However, Kutchko et al. (2008) predicted the extent of penetration from supercritical $\mathrm{CO}_{2}$ alteration would exceed that of exposure to $\mathrm{CO}_{2}$-saturated brine within 30 years because of more linear increases in penetration depth for cement exposed to supercritical $\mathrm{CO}_{2}$ than cement exposed to $\mathrm{CO}_{2}$ saturated water. Although penetration depth is mostly negligible for a cement column exposed to supercritical $\mathrm{CO}_{2}$ for 5 months, some spatially isolated degradation zone was also identified (Figure 3.12), which could be caused by condensed droplets of surface moisture on the outside surface of the cement sample (Kutchko et al. 2008).

After a 5-month reaction at high P-T conditions, BJH pore volume and BET surface areas all increased from 0.016 to $0.046 \pm 0.013 \mathrm{~cm}^{3} / \mathrm{g}(\mathrm{n}=5)$ and from 5.7 to $25.3 \pm 11.8 \mathrm{~m}^{2} / \mathrm{g}(\mathrm{n}=5)$, respectively, with cement exposure to supercritical $\mathrm{CO}_{2}$, while to $0.055 \pm 0.009 \mathrm{~cm}^{3} / \mathrm{g}(\mathrm{n}=5)$ and $36.3 \pm 8.0 \mathrm{~m}^{2} / \mathrm{g}(\mathrm{n}=5)$, respectively, with cement exposure to $\mathrm{CO}_{2}$ saturated water (Table 3.2, Figure 3.13).

Such increases in BJH pore volume and BET surface area suggest that dissolution was overall more dominant than precipitation over the course of a 5-month reaction by either supercritical $\mathrm{CO}_{2}$ or $\mathrm{CO}_{2}$ saturated water, but the lower BJH pore volume and BET surface area than those for an 1-month reaction by a factor of 2 2.5 (Table 3.2) suggests that calcite precipitation prevailed over portlandite dissolution during the reaction period between 1 month and 5 months. This is consistent with SEM and XMT images showing the presence of calcite crystals on the outside surface of cement column and in the inner degradation zone after a 5-month reaction (Figure 3.9 and Figure 3.12), unlike no or limited precipitation of calcite after an 1-month reaction at high P-T. Therefore, portlandite dissolution dominates the cement degradation during the early degradation stage for about a month, but calcite precipitation becomes more dominant with longer $\mathrm{CO}_{2}$ reaction. Nonetheless, it is uncertain whether long-term cement pore structure change for years and decades would be controlled by precipitation or dissolution. Similar to the 1-month reaction, the increase in $\mathrm{BJH}$ pore volume and surface area during the 5-month reaction was attributed to the rapid increase in nano-meter sized pores $(<20 \mathrm{~nm})$, while pores with size larger than $20 \mathrm{~nm}$ varied little (Figure 3.13). 
Table 3.2. BJH Pore Volume and BET Surface Area Before and After Cement- $\mathrm{CO}_{2}$ Reaction for 5 Months at High P-T Condition

\begin{tabular}{lccc}
\hline Vessel No. & \multicolumn{1}{c}{ Sample ID } & $\begin{array}{c}\text { BJH Pore } \\
\text { Volume } \\
\left(\mathrm{cm}^{3} / \mathrm{g}\right)\end{array}$ & $\begin{array}{c}\text { BET } \\
\text { Surface Area } \\
\left(\mathrm{m}^{2} / \mathrm{g}\right)\end{array}$ \\
\hline Vessel 1 & Unreacted cement & 0.016 & 5.722 \\
Vessel 3 & NRAP-3 top & 0.064 & 42.59 \\
& NRAP-6 top & 0.044 & 23.35 \\
Average for the & NRAP-15 top & 0.030 & 11.67 \\
Vessel 1 & NRAP-3 bottom & 0.053 & 29.96 \\
& NRAP-6 bottom & 0.039 & 18.68 \\
Vessel 3 & NRAP-11 bottom & 0.046 & 25.25 \\
& NRAP-15 bottom & 0.044 & 30.66 \\
& NRAP-23 bottom & 0.064 & 37.35 \\
Average for the bottom half & 0.055 & 44.02 \\
\hline
\end{tabular}
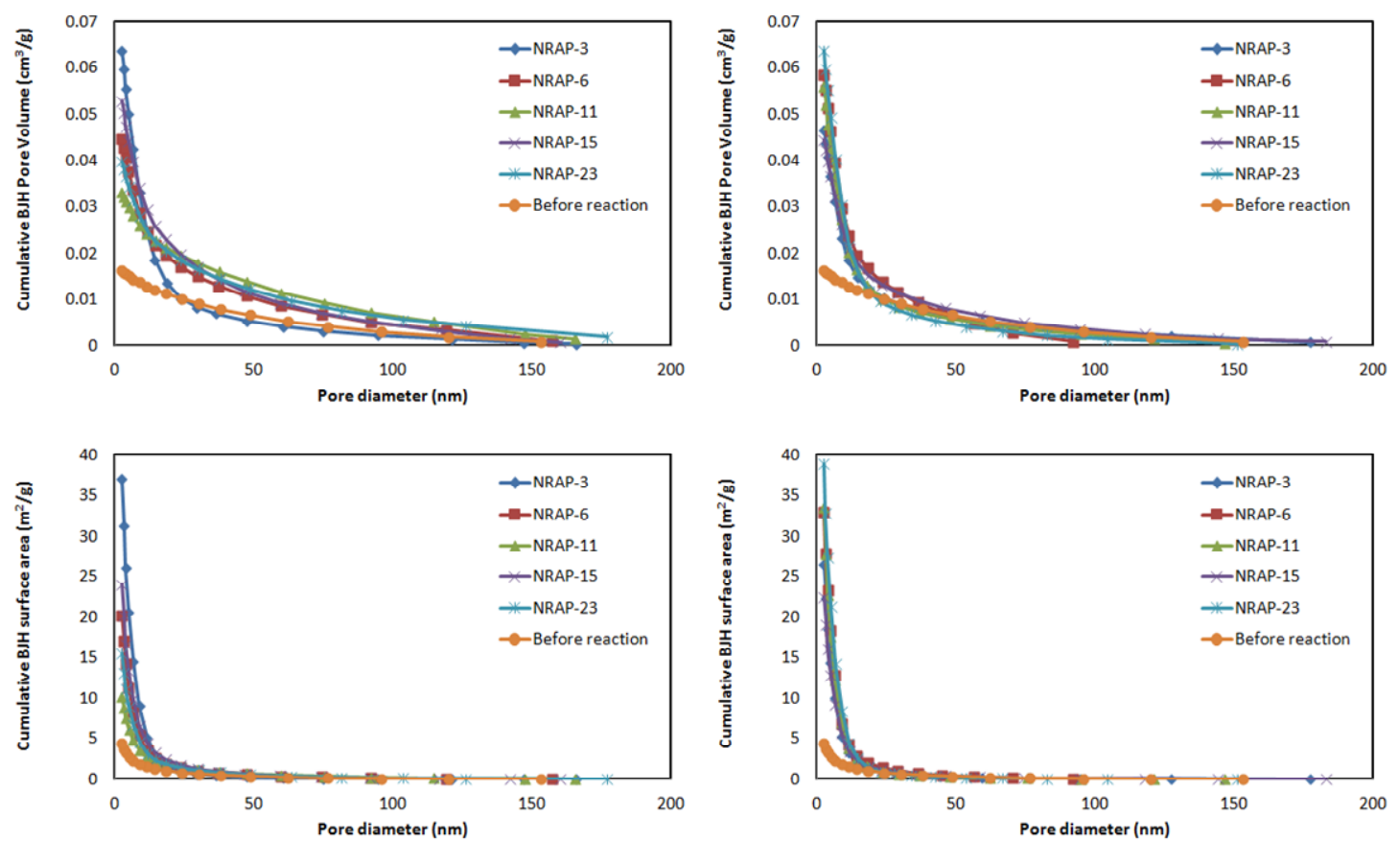

Figure 3.13. Cumulative BJH Pore Volume and Surface Area as a Function of Pore Diameter after Cement Reaction with Supercritical $\mathrm{CO}_{2}$ (left) and $\mathrm{CO}_{2}$ Saturated Water (right);

Cumulative BJH Pore Volume and Surface Area Prior to the Reaction is Also Indicated in Orange Symbols 
Although not consistent for all samples, the averages of $\mathrm{BJH}$ pore volume and BET surface area are higher for cement columns reacted with $\mathrm{CO}_{2}$ saturated water than those exposed to supercritical $\mathrm{CO}_{2}$ (Table 3.2), which suggests that cement degradation was more extensive with $\mathrm{CO}_{2}$ saturated water than with supercritical $\mathrm{CO}_{2}$. In spite of a large difference in the degradation depth between supercritical $\mathrm{CO}_{2}$ exposure and $\mathrm{CO}_{2}$ saturated water reaction based on XMT images (Figure 3.12), relatively small differences in BJH pore volume and BET surface area is found because these measurements are good to characterize only outer degradation zone due to limited $\mathrm{N}_{2}$ diffusion through nano-meter sized pores, not representing the pore structure of whole degradation zone.

\subsection{Low Pressure and Temperature Experiment}

After the reaction of a small-sized Portland cement column $(7 \mathrm{~mm}$ diameter $\times 20 \mathrm{~mm}$ long; water-tocement ratio $=0.38)$ with wet $\mathrm{CO}_{2}(\mathrm{~g})$ under a low $\mathrm{P}(0.1 \mathrm{MPa})-\mathrm{T}\left(20^{\circ} \mathrm{C}\right)$ condition for 1 month and 3 months, SEM-EDS and $\mu$-XRD identified the precipitation of micron-sized ( $10 \mu \mathrm{m}$ or less) calcite crystals on the outside surface of the cement column, as well as vaterite and portlandite (Figure 3.14).
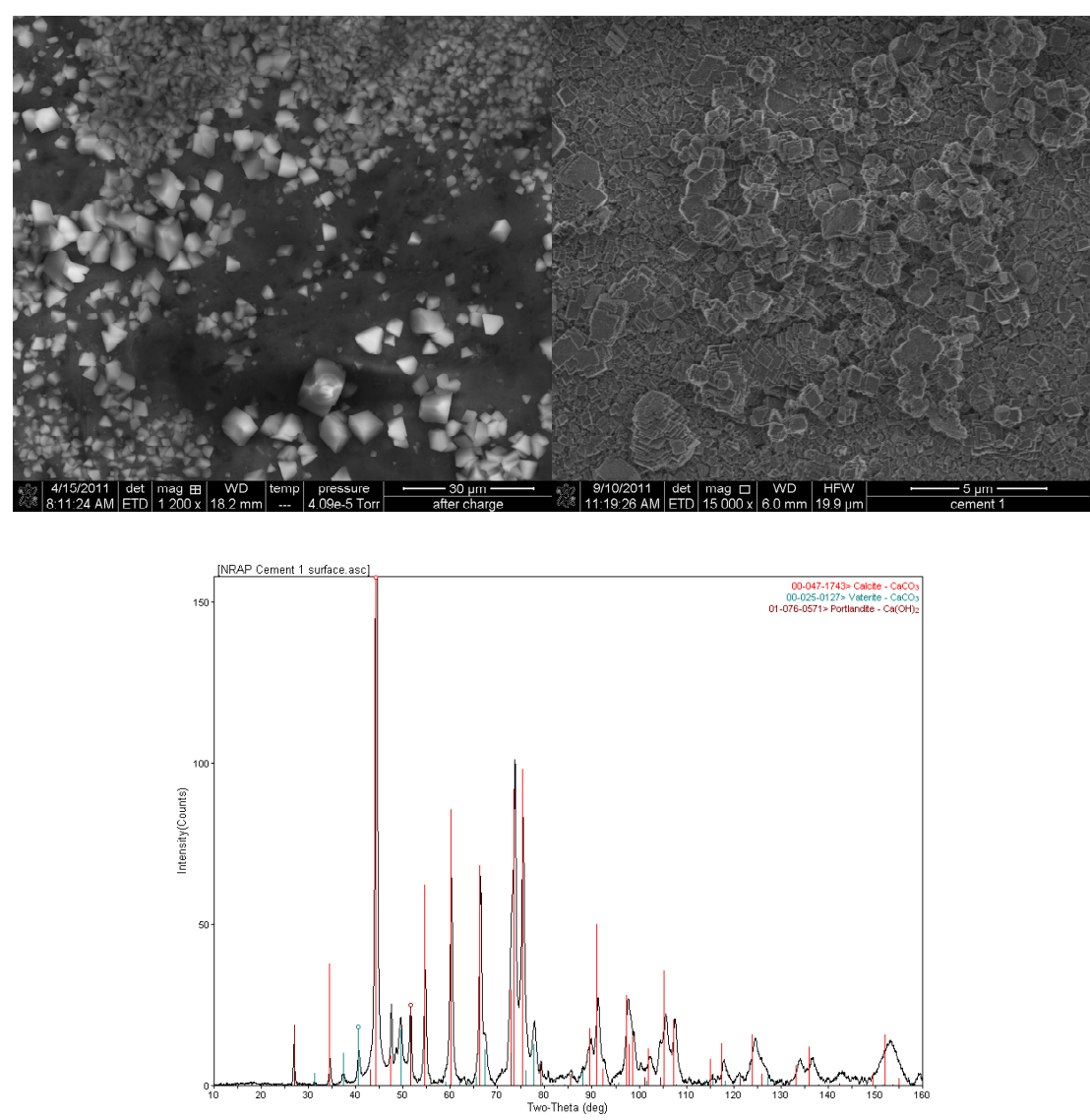

Figure 3.14. SEM Image Showing the Micron-Sized Calcite Precipitation on the Cement Surface After $\mathrm{CO}_{2}(\mathrm{~g})$ Reaction for 1 Month (top left) and 3 Months (top right), as well as XRD Pattern Showing Calcite as a Major Precipitate, as well as Vaterite as a Minor Precipitate (bottom)

Such calcite precipitation, widely covering the cement surface, was likely caused by the reaction of wet $\mathrm{CO}_{2}$ diffusing into cement pores with $\mathrm{Ca}^{2+}$ leached from $\mathrm{Ca}(\mathrm{OH})_{2}$ of cement matrix. Because the 
cement sample was reacting with wet $\mathrm{CO}_{2}(\mathrm{~g})$, not directly contacting water, and consequently leached $\mathrm{Ca}^{2+}$ was not diffused away from the cement surface, it seems the pores of the cement surface were easily saturated with respect to calcite.

Unlike high P-T reaction with supercritical $\mathrm{CO}_{2}$ or $\mathrm{CO}_{2}$ saturated water, BET surface area and $\mathrm{BJH}$ pore volume continued to decrease during a 3-month reaction with $\mathrm{CO}_{2}(\mathrm{~g})$ at low P-T conditions (Table 3.1). BJH pore volume and BET surface area were initially $8.0 \mathrm{~cm}^{3} / \mathrm{g}$ and $0.033 \mathrm{~m}^{2} / \mathrm{g}$, respectively, and decreased to $3.9 \mathrm{~cm}^{3} / \mathrm{g}$ and $0.013 \mathrm{~m}^{2} / \mathrm{g}$ after an 1-month reaction, and then to $2.4 \mathrm{~cm}^{3} / \mathrm{g}$ and $0.005 \mathrm{~m}^{2} / \mathrm{g}$ after the 3-month reaction (Table 3.1). Such continuous decrease in BJH pore volume and BET surface area over 3 months (Figure 3.15, Table 3.1) seems to result from precipitation of micron-sized calcite crystals on the outside surface of the cement column (Figure 3.14). After $\mathrm{CO}_{2}(\mathrm{~g})$ reaction for 1 month, there was a major chemical composition change in $\mathrm{Ca}$ and $\mathrm{C}$ atom $\%$ for the outside cement surface; $\mathrm{Ca}$ atom $\%$ decreased from $31 \%$ to $17 \%$, while $\mathrm{C}$ atom $\%$ increased from $10 \%$ to $25 \%$ (Table 3.3). In contrast, nearly invariable $\mathrm{Ca}(\sim 19 \%)$ and $\mathrm{C}(\sim 11 \%)$ atom $\%$ from inner to outer zones of the cross-section of the cement column suggests that little cement degradation by $\mathrm{CO}_{2}(\mathrm{~g})$ reaction has occurred inside the cement column for 3 months (Figure 3.16). Given the total porosity of the duplicate cement column (measured by Core Laboratories, Houston, Texas) is $31 \%$, the decrease of BJH pore volume can result in a total porosity decrease from $31 \%$ to $28 \%$ in 1 month, then to $26 \%$ in 3 months.
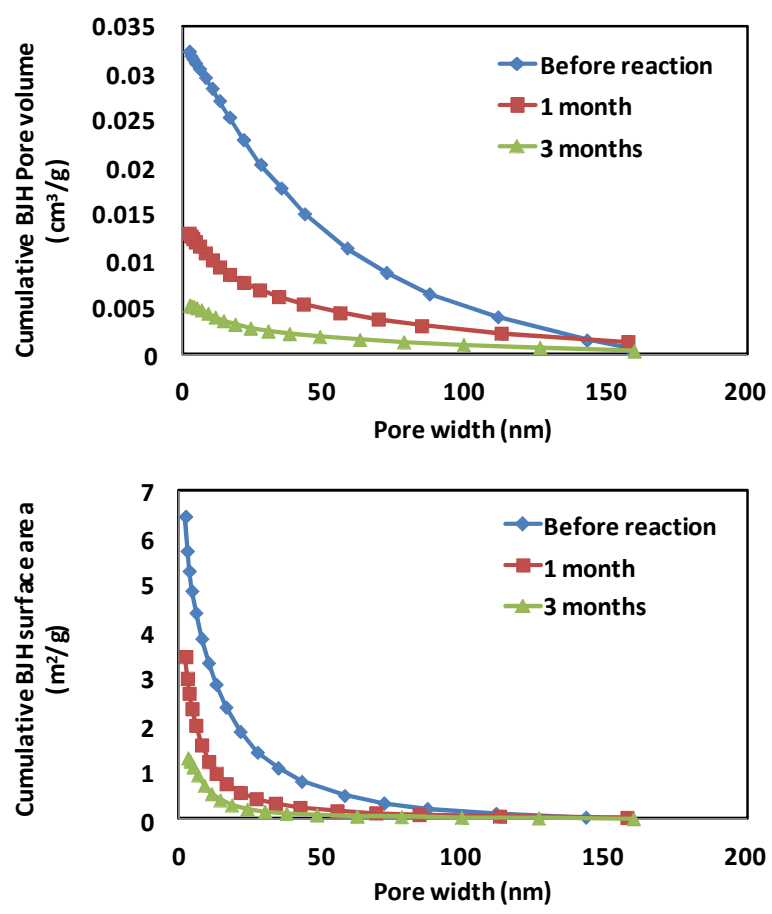

Figure 3.15. Change of Cumulative BJH Pore Volume and Surface Area as a Function of Pore Width as the Result of Moisturized $\mathrm{CO}_{2}(\mathrm{~g})$ Reaction for 1 to 3 Months 


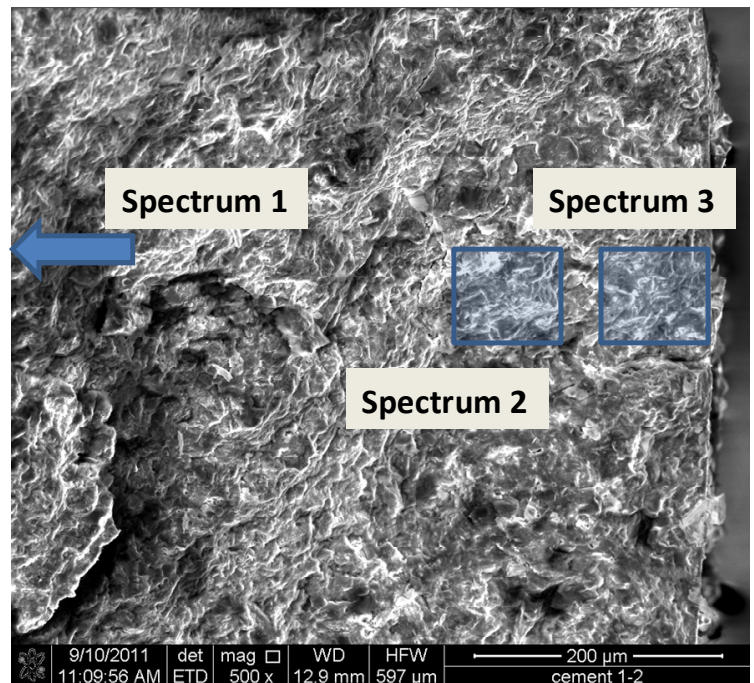

\begin{tabular}{cccc} 
Element & Spectrum 1 & Spectrum 2 & Spectrum 3 \\
\hline \hline C K & 11.3 & 10.9 & 12.5 \\
O K & 60.5 & 58.9 & 57.6 \\
Mg & 0.0 & 0.5 & 0.5 \\
AlK & 1.5 & 1.7 & 1.6 \\
SiK & 6.5 & 7.0 & 6.9 \\
S K & 0.8 & 0.8 & 0.9 \\
CaK & 19.0 & 19.7 & 19.4 \\
FeK & 0.6 & 0.6 & 0.6 \\
\hline
\end{tabular}

Figure 3.16. SEM Images and EDS Data for Horizontal Cross-Section of a Cement Column After $\mathrm{CO}_{2}(\mathrm{~g})$ Reaction for 3 Months; Spectrum 1 is from the Center of the Cross-Section

Table 3.3. SEM-EDS for the Outside Surface of a Cement Column for Low P-T Experiment Before and After $\mathrm{CO}_{2}$ Reaction

\begin{tabular}{ccc}
\hline Element & $\begin{array}{c}\text { Cement Before } \mathrm{CO}_{2} \\
\text { Reaction }\end{array}$ & $\begin{array}{c}\text { Cement After } \mathrm{CO}_{2} \\
\text { Reaction for } \\
1 \text { month }\end{array}$ \\
\hline $\mathrm{C} \mathrm{K}$ & 9.7 & 25.2 \\
$\mathrm{O} \mathrm{K}$ & 50.5 & 52.0 \\
$\mathrm{AlK}$ & 1.2 & 0.6 \\
$\mathrm{SiK}$ & 5.1 & 2.8 \\
$\mathrm{~S} \mathrm{~K}$ & 0.8 & 0.2 \\
$\mathrm{~K} \mathrm{~K}$ & 0.6 & 0.7 \\
$\mathrm{CaK}$ & 31.3 & 16.6 \\
$\mathrm{FeK}$ & 0.9 & 0.2 \\
$\mathrm{NaK}$ & -- & 1.3 \\
$\mathrm{MgK}$ & -- & 0.4 \\
\hline
\end{tabular}

\subsection{Effective Liquid Permeability Measurement by X-Ray Microtomography Image of Potassium lodide (KI) Injection}

A novel method to measure effective liquid permeability of a cement column using XMT is under development by Pacific Northwest National Laboratory (PNNL). Cement column samples prepared with $\mathrm{KI}$ solution ( 0.8 and $1.2 \mathrm{M}$ or 13 and $20 \mathrm{wt} . \%)$ showed higher contrast between liquid-filled pores (bright color) and solid phase (dark color) than a sample prepared without KI (Figure 3.17). 
OM KI

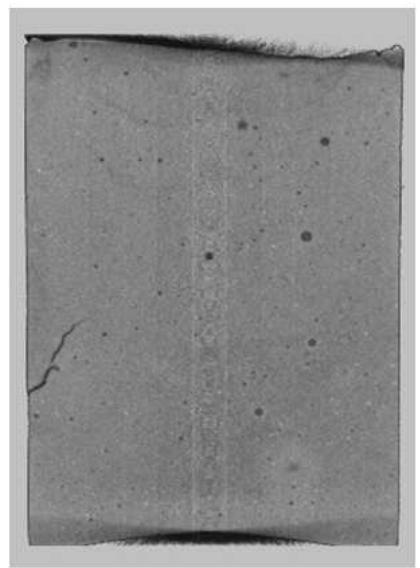

$0.8 \mathrm{M} \mathrm{KI}$

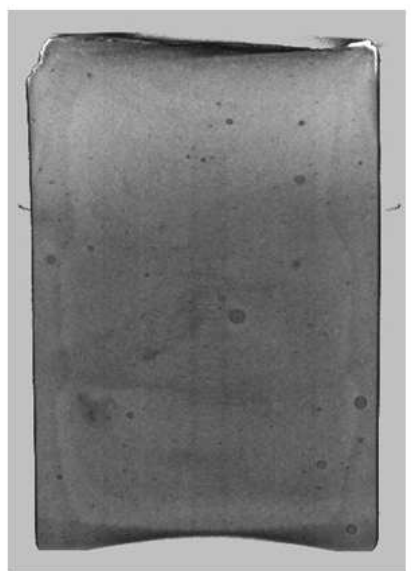

$1.2 \mathrm{M} \mathrm{KI}$

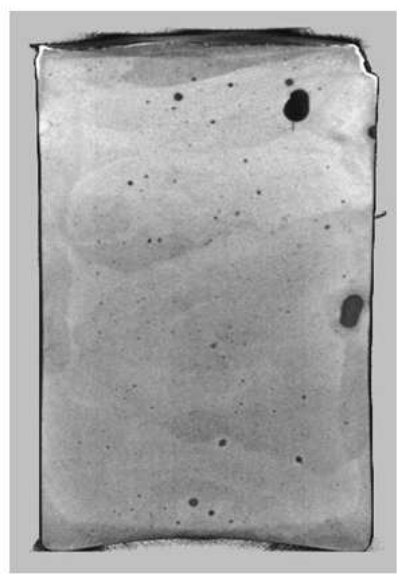

Figure 3.17. XMT Images Showing the Effect of KI Solution on the Contrast Between Liquid-Filled Pores and Solid Phase in Cement Samples (bright colored area, black dots, and gray colored area represent liquid-filled pores, air-filled pores, and solid phase, respectively)

Using Darcy's law (Equation 1), effective liquid permeability can be estimated by XMT image of KI solution transport after injecting KI solution into a cement column at an elevated pressure ( $10 \mathrm{psi})$.

$$
\text { Darcy's Law: } q=-k / \mu \times \Delta P
$$

where $\quad \mathrm{q}=$ Darcy flux (discharge per unit area; $\mathrm{m} / \mathrm{s}$ )

$\mathrm{k}=$ permeability $\left(\mathrm{m}^{2}\right.$ or darcy, $\left.\mathrm{D}\right)$

$\mu=$ viscosity $\left(0.00091 \mathrm{~Pa} \cdot \mathrm{s}\right.$ at $\left.20^{\circ} \mathrm{C}\right)$

$\Delta \mathrm{P}=$ pressure gradient vector.

Preliminary results from the KI injection experiment indicate the permeability of a cement column sample (water-to-cement ratio $=0.38$ ) is $4 \sim 8 \mu \mathrm{D}$ (Figure 3.18). These results are much lower than air permeability $(0.576 \mathrm{mD})$ for the duplicate cement column measured by Core Laboratories. Such a large difference between air and liquid permeabilities could be attributed to the drying of the sample at $115^{\circ} \mathrm{C}$ before the measurement by Core Laboratories, contrary to liquid permeability measurement without ovendrying by PNNL. PNNL will compare the effective liquid permeability of a cement column before and after $\mathrm{CO}_{2}$ reaction under high P-T and low P-T conditions. This method can provide information on the spatial distribution of $\mathrm{CO}_{2}(\mathrm{~g})$ permeability along degradation zones in a cement column. The results obtained from PNNL through laboratory experiments under a variety of pressure and temperature conditions will be used to develop a stronger and more predictable wellbore leakage risk model. 

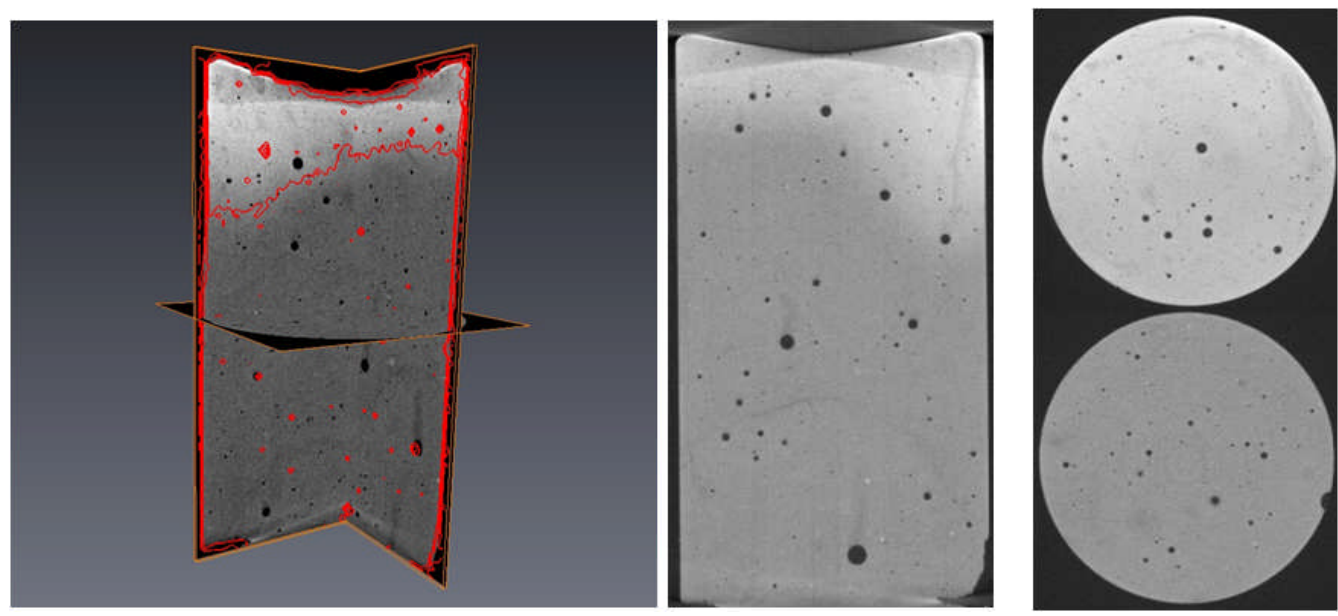

Figure 3.18. XMT Image Showing the Advection of KI Solution ( $30 \mathrm{wt} . \%$; bright color) Through Pores of a Cement Column (water-to-cement ratio $=0.38$ ) at 9 psi for 114 Hours

Permeability change can be also estimated from a power law permeability-porosity relationship from David et al. (1994) (Equation 2):

$$
\mathrm{K}=\mathrm{K}_{0} \times\left(\Phi / \Phi_{0}\right)^{\alpha}
$$

where $\Phi / \Phi_{0}$ are porosity values corresponding to the permeabilities $\mathrm{K}$ and $\mathrm{K}_{0}$, respectively. The porosity sensitivity exponent, $\alpha$ is reported to vary between 1.1 and 25.4 for different materials and evolution process. Ghabezloo et al. (2009) reported the porosity sensitivity exponent of the power-law is evaluated equal to 11 for hardened cement paste. Using the exponent of 11 , the permeability of cement column with water-to-cement ratio of 0.38 is predicted to increase from $0.58 \mathrm{mD}$ to $34.74 \mathrm{mD}$ after an 1-month reaction with $\mathrm{CO}_{2}$ saturated water at high $\mathrm{P}-\mathrm{T}$ as a result of porosity increase from $31 \%$ to $45 \%$, whereas the permeability decreases to $0.19 \mathrm{mD}$ in 1 month, then to $0.08 \mathrm{mD}$ in 3 months with porosity decrease from $31 \%$ to 28 and $26 \%$ when the cement was reacted with $\mathrm{CO}_{2}(\mathrm{~g})$ at low P-T.

\subsection{Geochemical Modeling of Cement Degradation}

A PHREEQC geochemical modeling of portlandite $\left[\mathrm{Ca}(\mathrm{OH})_{2}\right]$ carbonation in bulk water equilibrated with $\mathrm{CO}_{2}$ under $10 \mathrm{MPa}$ pressure at $50^{\circ} \mathrm{C}$ using MINTEQ version 4 database was performed, assuming that portlandite consists of $15 \%$ of total cement mass (Kutchko et al. 2007). The modeling result shows that calcite precipitation is predicted after $1.2 \mathrm{~g}$ of each cement column (total $13 \mathrm{~g}$ for the bottom half of a cement column) is reacted, which corresponds to degradation depth of $\sim 0.3 \mathrm{~mm}$ in each cement column $(14 \mathrm{~mm}$ diameter $\times 90 \mathrm{~mm}$ long; water-to-cement ratio $=0.33)$ in vessel 3 or vessel 4 , which contains 3 cement columns with $130 \mathrm{~mL}$ synthetic groundwater (Figure 3.19). This is consistent with the XMT images and SEM-EDS data showing that calcite precipitation has extensively occurred in those cement matrix for 5 months with degradation depth of $\sim 3.5 \mathrm{~mm}$, far exceeding $0.3 \mathrm{~mm}$ of degradation depth for saturation with respect to calcite. After the system is saturated with respect to calcite, $\mathrm{pH}$ is predicted to be buffered to $\sim 5.5$ (Figure 3.A). In contrast, for a small-sized cement column $(7 \mathrm{~mm}$ diameter $\times 20 \mathrm{~mm}$ long; water-to-cement ratio $=0.38$; total mass $=\sim 1.6 \mathrm{~g}$ ) in vessel 5 containing $130 \mathrm{~mL}$ synthetic groundwater, calcite precipitation is unlikely to occur after the cement degradation of $\sim 1 \mathrm{~mm}$ depth (or $0.79 \mathrm{~g}$ of cement reaction) for 1 month under the same high pressure and temperature conditions. This is 
in agreement with what was observed in the XMT image (Figure 3.5), which indicated a 1-mm degradation zone with low density likely resulting from dissolution of $\mathrm{Ca}(\mathrm{OH})_{2}$ with little precipitation of calcite. PHREEQC modeling does not predict calcite precipitation even after all mass $(\sim 1.6 \mathrm{~g})$ of the cement column is reacted, which results in a saturation index of -0.66 with respect to calcite and a $\mathrm{pH}$ of $\sim 4.5$ (Figure 3.19B). This indicates that even long-term cement $-\mathrm{CO}_{2}$ reaction would not form fully carbonated zones in the cement matrix of this small-sized cement column. A major difference between vessel 1-4 and vessel 5 is a higher ratio of solid (cement)-to-solution (synthetic groundwater) in vessel 14 than vessel 5. The solid-to-solution ratio in vessel $1-4$ was $0.3 \mathrm{~g} / \mathrm{mL}$, whereas the ratio was $0.01 \mathrm{~g} / \mathrm{mL}$ in vessel 5. The geochemical modeling results suggest that calcite precipitation in cement matrix is unlikely at $10 \mathrm{MPa}$ and $50^{\circ} \mathrm{C}$ with the solid-to-solution ratio below $0.025 \mathrm{~g} / \mathrm{mL}$ under static conditions (Figure 3.19C). In the field wellbore environment, the solid-to-solution ratio is most likely much higher than $0.025 \mathrm{~g} / \mathrm{mL}$, suggesting extensive calcite precipitation in wellbore cement is likely to occur in the carbon sequestration field site. Heavy carbonation to form calcite is indeed observed from wellbore cement after a 30-year old $\mathrm{CO}_{2}$-flooding operation at the SACROC unit, West Texas (Carey et al. 2007). The researchers' modeling result of bulk chemical reaction between portlandite and acidic carbonated water highlights the importance of experimental condition that can represent the in-situ field condition to perform realistic risk assessments of $\mathrm{CO}_{2}$ leakage through wellbore. Therefore, laboratory experiments of cement- $\mathrm{CO}_{2}$ reactions at unrealistic solid-to-solution ratios not representing the field wellbore environment would fail to simulate and predict the cement degradation under carbon sequestration field conditions.

A

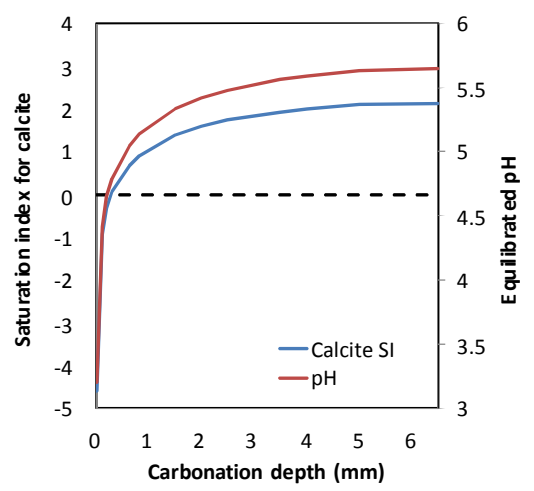

B

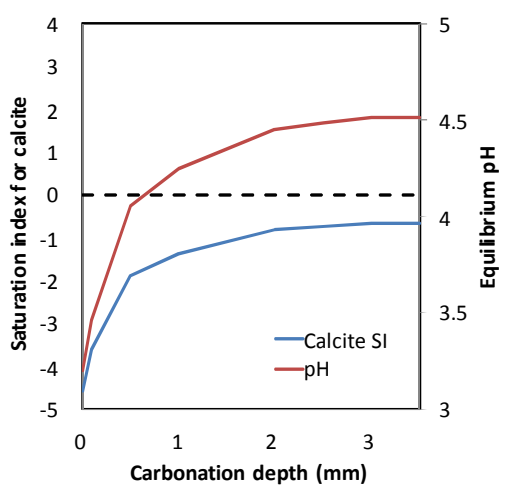

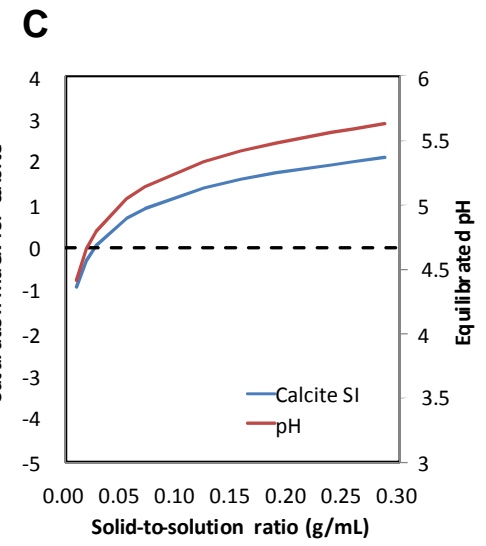

Figure 3.19. Bulk Geochemical Reaction Modeling of Cement Degradation in (A) Vessel 1-4 and (B) Vessel 5 by $\mathrm{CO}_{2}$ Saturated Water at $50^{\circ} \mathrm{C}$ and $10 \mathrm{MPa}$, As Well As (C) the Saturation Index with Respect to Calcite as a Function of Solid-to-Solution Ratio

One-dimensional transport modeling was performed to simulate the propagation of cement degradation as a function of penetration depth. Dispersion in cement matrix is assumed to be minimal with dispersivity of $2 \times 10^{-9} \mathrm{~m}$. Portlandite and calcite were addressed in the modeling, but C-S-H was not considered due to the lack of thermodynamic database for this semi-amorphous gel-like material. Dissolution of C-S-H and conversion to amorphous silica gel are expected after all portlandite and calcites are consumed so that the cement no longer has the ability to buffer the pH (Kutchko et al. 2007). Transport of carbonated water in equilibrium with $\mathrm{CO}_{2}$ at $10 \mathrm{MPa}$ through pores of a cement column with total radius of $7 \mathrm{~mm}$ is modeled to simulate the degradation of cement columns (water-to-cement ratio = 0.33 ) in vessel 3 or 4 . Cement pore water in equilibrium with portlandite is predicted to have initial $\mathrm{pH}$ of 
11.6, which drops to 3.2 as carbonate water penetrates through the cement matrix. At the degradation front where $\mathrm{pH}$ decreases rapidly, $\mathrm{Ca}$ concentration is predicted to increase steeply to $1.7 \mathrm{~mol} / \mathrm{L}$ (Figure 3.20). The high $\mathrm{Ca}$ zone is predicted to become thicker as a function of penetration depth. For instance, the thickness of high Ca zone increases from $\sim 0.5 \mathrm{~mm}$ with penetration depth of $0.8 \mathrm{~mm}$ to $\sim 1.5 \mathrm{~mm}$ with penetration depth of $6.5 \mathrm{~mm}$. When the penetration depth is $3.5 \mathrm{~mm}$, which is the observed penetration depth by XMT after a 5-month reaction, the high Ca zone where calcite precipitation is predicted is located approximately between 2.5 and $3.5 \mathrm{~mm}$ from the boundary, while calcite dissolution is predicted to be dominated in the outer zone with $\sim 2.5 \mathrm{~mm}$ thickness (Figure 3.20). This is consistent with SEMEDS analyses indicating inner degradation zone with calcite precipitation and outer degradation zone of calcite dissolution. As carbonate water penetrates the cement matrix, carbonate concentration in cement pores is elevated to $1.8 \mathrm{~mol} / \mathrm{L}$, and the thickness of high carbonate zone increases as a function of penetration depth (Figure 3.20). In the zone where pore water $\mathrm{Ca}$ and carbonate concentrations are both high and $\mathrm{pH}$ is neutral or alkaline, the cement pore water is predicted to be supersaturated with respect to calcite $(\mathrm{SI}=5)$. The zone of calcite precipitation changes in terms of thickness and location as a function of penetration depth. The calcite precipitation zone becomes thicker with increasing penetration depth, corresponding to thickness of high $\mathrm{Ca}$ zone, and the zone moves toward the center of the cement matrix. In the outer zone, modeling shows that calcite precipitation occurs in the early stage of carbonation, and then the precipitated calcite dissolves out again with increasing penetration of carbonate water.

The modeling results for degradation of a small-sized cement column (water-to-cement ratio $=0.38$ ) in vessel 5 also show a similar change in $\mathrm{pH}$ and $\mathrm{Ca}$ concentration as a function of penetration depth, but increases of $\mathrm{Ca}$ concentration is about an order of magnitude lower than that for cement degradation in vessel 3-4 (Figure 3.21). The Ca concentration at the degradation front continues to increase from 0.04 to $0.28 \mathrm{~mol} / \mathrm{L}$ as the penetration depth increases from 0.4 to $3.5 \mathrm{~mm}$. With penetration depth of $1 \mathrm{~mm}$, which is the observed penetration depth for 1 month, the Ca concentration at the degradation front is predicted to be $0.08 \mathrm{~mol} / \mathrm{L}$. The lower Ca concentration in the pore water of the cement column in vessel 5 than that of cement columns in vessel 3-4 resulted in a lower saturation index with respect to calcite (Figure 3.21). In addition, the thickness of calcite precipitation zone is predicted to be thin with less than $0.5 \mathrm{~mm}$-thickness. This is consistent with XMT and SEM-EDS data, suggesting portlandite dissolution is dominant with some local precipitation of calcite in the degradation zone of the small-sized cement column in vessel 5 after an 1-month reaction (Figure 3.3 and Figure 3.5). One-dimensional-transport modeling results also suggest that propagation of cement degradation is dependent on the solid-tosolution ratio of the cement and underscores the importance in realistic experimental setting that can represent the in situ wellbore environment to perform accurate assessment of the long-term risk of $\mathrm{CO}_{2}$ leakage through the wellbore cement. 

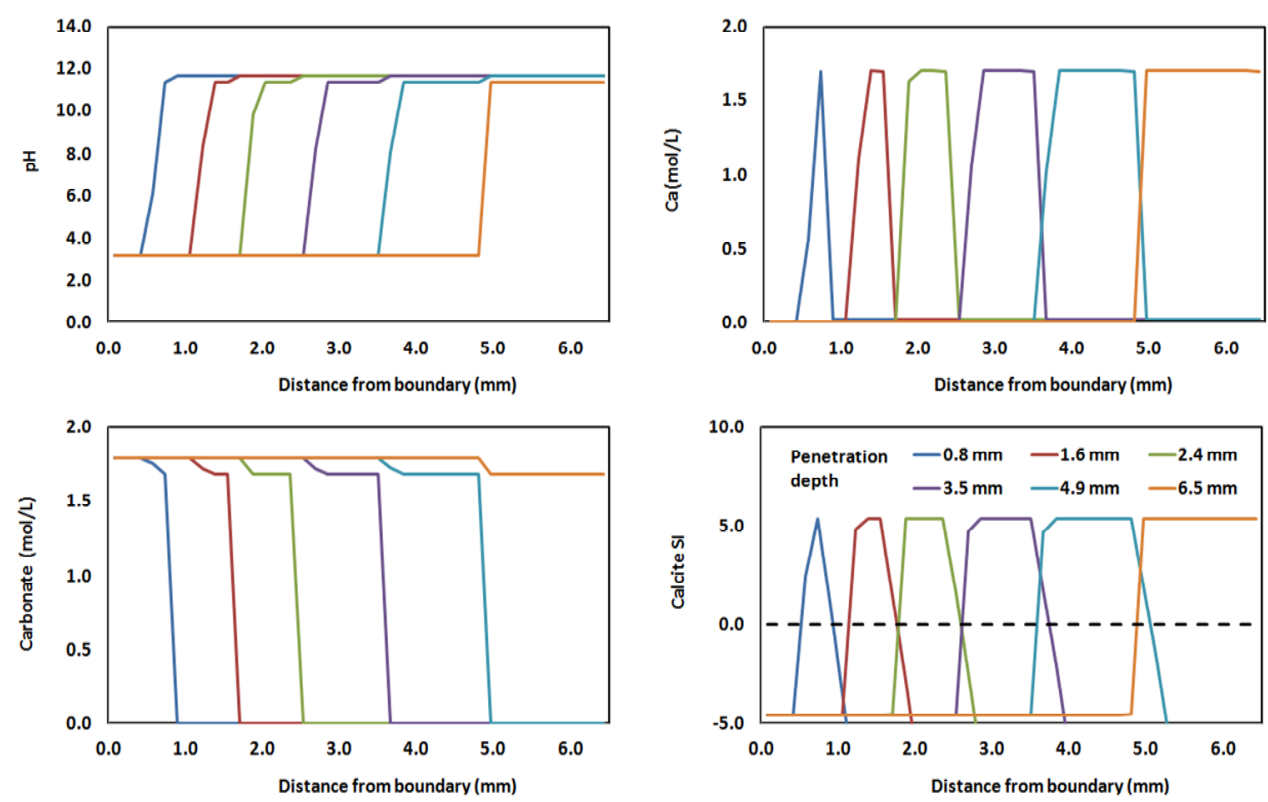

Figure 3.20. One-Dimensional Transport Geochemical Modeling of Cement Degradation by $\mathrm{CO}_{2}$ Saturated Water at $50^{\circ} \mathrm{C}$ and $10 \mathrm{MPa}$ as a Function of Penetration Depth in Vessel 3 or 4
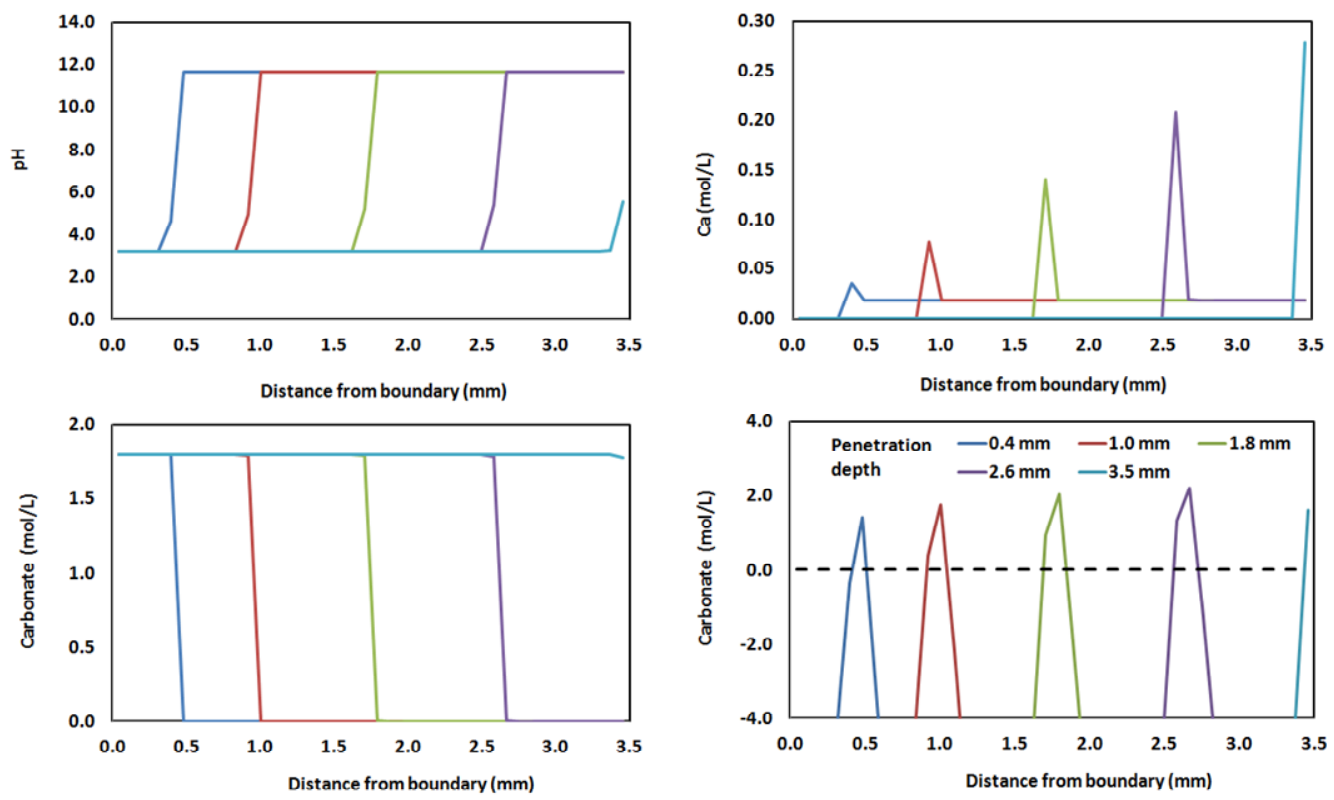

Figure 3.21. One-Dimensional Transport Geochemical Modeling of Cement Degradation by $\mathrm{CO}_{2}$ Saturated Water at $50^{\circ} \mathrm{C}$ and $10 \mathrm{MPa}$ as a Function of Penetration Depth in Vessel 5 


\subsection{Conclusion}

The reaction of Portland cement- $\mathrm{CO}_{2}(\mathrm{~g})$ saturated groundwater under carbon sequestration (high P-T) conditions for 1 to 5 months resulted in an orange-colored degraded zone consisting of two distinctive zones: an outer degraded zone with $\mathrm{C}$ atom $\%>\mathrm{Ca}$ atom $\%$ and an inner degraded zone with $\mathrm{Ca}$ atom $\%$ $\approx \mathrm{C}$ atom $\%$. The outer degraded zone is highly porous and fractured due to the dissolution of calcite and $\mathrm{C}-\mathrm{S}-\mathrm{H}$ by carbonic acid attack, leading to the increase in BJH pore volume and BET surface area. XMT images revealed the cement degradation was more extensive by the reaction with $\mathrm{CO}_{2}(\mathrm{~g})$ saturated water than by exposure to supercritical $\mathrm{CO}_{2}$. Under high P-T, 1-month and 5-month reactions with $\mathrm{CO}_{2}$ saturated water resulted in degradation depth of approximately $1 \mathrm{~mm}$ and $3.5 \mathrm{~mm}$, respectively. Cement$\mathrm{CO}_{2}(\mathrm{~g})$ reactions at $100 \%$ humidity under low P-T conditions for 1-3 months resulted in precipitation of micron-sized calcite on the cement surface, which resulted in continuous decrease in BJH pore volume and BET surface area. A novel method using an XMT image after KI injection into a cement column determined the effective liquid permeability of an unreacted cement column with w/c of 0.38 to be $4 \sim 8$ $\mu \mathrm{D}$, and this method will be used to understand the permeability change of Portland cement by $\mathrm{CO}_{2}$ reaction under variable P-T conditions. Geochemical modeling suggests the cement- $\mathrm{CO}_{2}$ reaction experiment at solid-to-solution ratio representing in-situ wellbore environment is essential for accurate prediction of the long-term wellbore degradation and potential $\mathrm{CO}_{2}$ leakage. 



\subsection{References}

Bachu S and DB Bennion. 2009. "Experimental Assessment of Brine and/or $\mathrm{CO}_{2}$ Leakage Through Well Cements at Reservoir Conditions." International Journal of Greenhouse Gas Control 3:494-501.

Bachu S and TL Watson. 2009. "Review of failures for wells used for $\mathrm{CO}_{2}$ and acid gas injection in Alberta, Canada." Energy Procedia 1:3531-3537.

Bachu S. 2003. "Screening and Ranking of Sedimentary Basins for Sequestration of $\mathrm{CO}_{2}$ in Geological Media." Environmental Geology 44:277-289.

Barlet-Gouédard V, G Rimmelé, B Goffe, and O Porcherie. 2006. "Mitigation Strategies for the Risk of $\mathrm{CO}_{2}$ Migration through Wellbores." IADC/SPE Drilling Conference, February 21-23 2006, Miami, Florida.

Bruant R, A Guswa, MA Celia, and CA Peters. 2002. "Safe Storage of $\mathrm{CO}_{2}$ in Deep Saline Aquifers." Environmental Science \& Technology 36:241A-245A.

Crow W, JW Carey, S Gasda, DB Williams, and M Celia. 2010. "Wellbore Integrity Analysis of a Natural $\mathrm{CO}_{2}$ Producer.” International Journal of Greenhouse Gas Control 4:186-197.

David C, TF Wong, W Zhu, and J Zhang. 1994. "Laboratory Measurement of Compaction-induced Permeability Change in Porous Rocks: Implications for the Generation and Maintenance of Pore Pressure Excess in the Crust." Pure and Applied Geophysics 143: 425-456.

Duguid A and GW Scherer. 2010. "Degradation of Oil Well Cement Due to Exposure to Carbonated Brine." International Journal of Greenhouse Gas Control 4:546-560.

Fernandez Bertos M, SJR Simons, CD Hills, and PJ Carey. 2004. "A Review of Accelerated Carbonation Technology in the Treatment of Cement-Based Materials and Sequestration of $\mathrm{CO}_{2}$." Journal of Hazardous Materials B112:193-205.

Gasda SE, S Bachu, and MA Celia. 2004. "Spatial Characterization of the Location of Potentially Leaky Wells Penetrating a Deep Saline Aquifer in a Mature Sedimentary Basin.” Environmental Geology 46:707-720.

Ghabezloo S, J Sulem, J Saint-Marc 2009. "Evaluation of a Permeability-Porosity Relationship in a Low Permeability Creeping Material Using a Single Transient Test." International Journal of Rock Mechanics and Mining Sciences 46: 761-768.

Haga K, S Sutou, M Hironaga, S Tanaka, and S Nagasaki. 2005. "Effects of Porosity on Leaching of Ca from Hardened Ordinary Portland Cement Paste." Cement and Concrete Research 35: 1764-1775.

Haselbach LM and S Ma. 2008. "Potential Carbon Adsorption on Concrete: Surface XPS Analyses." Environmental Science \& Technology 42:5329-5334. 
Kutchko B, B Strazisar, GV Lowry, DA Dzombak, and N Thaulow. 2008. "Rate of $\mathrm{CO}_{2}$ Attack on Hydrated Class H Well Cement under Geologic Sequestration Conditions." Environmental Science \& Technology 42:6237-6242.

Kutchko B, B Strazisar, GV Lowry, DA Dzombak, and N Thaulow. 2007. "Degradation of Well Cement by $\mathrm{CO} 2$ under Geologic Sequestration Conditions." Environmental Science \& Technology 41:4787-4792.

Kutchko B, B Strazisar, N Huerta, GV Lowry, DA Dzombak, and N Thaulow. 2009. " $\mathrm{CO}_{2}$ Reaction with Hydrated Class H Well Cement under Geologic Sequestration Conditions: Effects of Fly ash Admixtures.” Environmental Science \& Technology 43:3947-3952.

Liteanu E and CJ Spiers. 2011. "Fracture healing and transport properties of wellbore cement in the presence of supercritical $\mathrm{CO}_{2}$." Chemical Geology 281:195-210.

Little $\mathrm{M}$ and RB Jackson. 2010. "Potential Impacts of Leakage from Deep $\mathrm{CO}_{2}$ Geosequestration on Overlying Freshwater Aquifers.” Environmental Science \& Technology 44:9225-9232.

Nelson EB. 1990. Well Cementing. Schlumberger Educational Services, Sugar Land, Texas.

Neville AM. 2004. Properties of Concrete, $4^{\text {th }}$ ed. John Wiley and Sons, New York.

Rimmele G, V Barlet-Gouedard, O Porcherie, B Goffe, and F Brunet. 2008. "Heterogeneous Porosity Distribution in Portland Cement Exposed to $\mathrm{CO}_{2}$-Rich Fluids." Cement and Concrete Research 38:1038-1048.

Scherer GW, MA Celia, JH Prevost, S Bachu, RG Bruant, A Duguid, R Fuller, SE Gasda, M Radonjic, and W Vichit-Vadakan. 2005. "Leakage of $\mathrm{CO}_{2}$ Through Abandoned Wells: Role of Corrosion of Cement." In $\mathrm{CO}_{2}$ Capture Project Technical Results, D Thomas and S Benson (Eds.), Elsevier, Amsterdam, Vol. 2, pp. 827-848.

Solomon S, D Qin, M Manning, M Marquis, K Averyt, MMB Tignor, HL Miller Jr., and Z Chen (eds). 2007. IPCC Climate Change 2007: The Physical Science Basis. Contribution of Working Group I to the Fourth Assessment Report of the Intergovernmental Panel on Climate Change, Cambridge University Press.

U.S. Department of Energy (DOE). 2007. Carbon Sequestration Technology Roadmap and Program Plan. U.S. Department of Energy, Office of Fossil Energy, Washington, D.C. Accessed November 1, 2011, at http://www.google.com/url?q=http://www.netl.doe.gov/technologies/carbon_seq/refshelf/project\%2520po rtfolio/2007/2007Roadmap.pdf\&sa=U\&ei=vRawTo2HE6LniALom6kb\&ved=0CBkQFjAA\&usg=AFQjC NEoCNSAzIXdf9ns8XhfTBrPxcrJPQ.

Wigand M, JP Kaszuba, JW Carey, and WK Hollis. 2009. "Geochemical Effects of $\mathrm{CO}_{2}$ Sequestration on Fractured Wellbore Cement at the Cement/Caprock Interface." Chemical Geology 265:122-133. 
Wilkin R and DC Digiulio. 2010. "Geochemical Impacts to Groundwater from Geologic Carbon Sequestration: Controls on $\mathrm{pH}$ and Inorganic Carbon Concentrations from Reaction Path and Kinetic Modeling.” Environmental Science Technology 44:4821-4827.

Wong RCK and KT Chau. 2005. "Estimation of Air Void and Aggregate Spatial Distributions in Concrete Under Uniaxial Compression Using Computer Tomography Scanning." Cement and Concrete Research 35: 1566-1576. 



\section{Distribution}

No. of

\section{Copies}

1 National Energy Technology Laboratory 626 Cochrans Mill Road

P.O. Box 10940

Pittsburgh, PA 15236

Brian Strazisar PDF

4 Los Alamos National Laboratory

P.O. Box 1663

Los Alamos, NM 87545

Bill Carey

PDF

Amy B. Jordan

PDF

Rajesh Pawar

PDF

Philip H. Stauffer

PDF

3 Lawrence Berkeley National Laboratory Earth Sciences Division

1 Cyclotron Road

Berkeley, CA 94720 USA

Jim Houseworth PDF

Preston D. Jordan PDF

Curtis M. Oldenburg PDF

2 Lawrence Livermore National Laboratory 7000 East Avenue

Livermore, CA 94550

Susan A. Carroll

Stuart Walsh

PDF

PDF
No. of

\section{Copies}

12 Local Distribution

Pacific Northwest National Laboratory

Thomas M Brouns PDF

Christopher F Brown PDF

Kirk Cantrell PDF

Omar Harvey PDF

Hun Bok Jung PDF

Pete McGrail PDF

Chris Murray PDF

Nik Qafoku PDF

Jeff Serne PDF

Hongbo Shao PDF

Charlotte Sullivan PDF

Wooyong Um PDF

Stephen Unwin PDF 




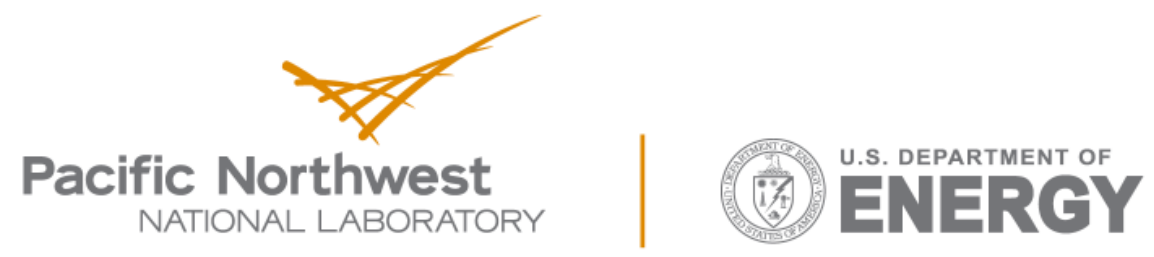

Proudly Operated by Battelle Since 1965

902 Battelle Boulevard

P.O. Box 999

Richland, WA 99352

1-888-375-PNNL (7665)

www.pnnl.gov 